\title{
RELIABILITY-BASED STRENGTH REDUCTION FACTOR FOR BOND
}

\author{
B y \\ David Darwin \\ Emmanuel K. Idun \\ Jun Zuo \\ Michael L. Tholen
}

\begin{abstract}
A Report on Research Sponsored by
THE CIVIL ENGINEERING RESEARCH FOUNDATION Contract No. 91-N6002

THE NATIONAL SCIENCE FOUNDATION

Research Grants No. MSS-9021066 and CMS-9402563

THE REINFORCED CONCRETE RESEARCH COUNCIL Project 56
\end{abstract}

STRUCTURAL ENGINEERING AND ENGINEERING MATERIALS

SL REPORT 95-5

\author{
UNIVERSITY OF KANSAS CENTER FOR RESEARCH, INC. \\ LAWRENCE, KANSAS \\ MAY 1995
}




\section{LEGAL NOTICE}

This report was prepared by the University of Kansas Center for Research, Inc. as an account of work sponsored by the Civil Engineering Research Foundation (CERF) and the National Science Foundation (NSF).

Neither CERF, nor any persons acting on behalf of either:

a. Makes any warranty or representation, express or implied, with respect to the accuracy, completeness, or usefulness of the information contained in this report, or that the use of any apparatus, method, or process disclosed in this report may not infringe third party rights; or

b. Assumes any liability with respect to the use of, or for damages resulting from the use of, any information, apparatus, method, or process disclosed in this report.

c. Makes any endorsement, recommendation or preference of specific commercial products, commodities or services which may be referenced in this report.

Any opinions, findings, and conclusions or recommendations expressed in this material are those of the authors and do not necessarily reflect the views of the National Science Foundation. 


\title{
RELIABILITY-BASED STRENGTH REDUCTION FACTOR FOR BOND
}

\begin{abstract}
The formulation and calculation of a reliability-based strength-reduction $(\phi)$ factor for developed and spliced bars is described. Conventional and high relative rib area bars, both with and without confining reinforcement, are considered. The $\phi$-factor is determined using statistically-based expressions for development/splice strength and Monte Carlo simulations of a range of beams.

A strength-reduction factor of 0.9 is obtained for the design expressions for development/splice length, based on a probability of failure in bond equal to about one-fifth of the probability of failure in bending or combined bending and compression. $\phi=0.9$ is incorporated into two expressions for development/splice length in a manner that is transparent to the user. A major advantage of each of the final expressions is that they provide identical values for development and splice length, removing the need to multiply development length by 1.3 or 1.7 to obtain the length of most splices.
\end{abstract}

Keywords: bond (concrete to reinforcement); bridge specifications; building codes; deformed reinforcement, development; lap connections; reinforcing steels; relative rib area; reliability; splicing; structural engineering; variability. 


\section{ACKNOWLEDGEMENTS}

Support for this research was provided by the Civil Engineering Research Foundation under CERF Contract No. 91-N6002, the National Science Foundation under NSF Grants No. MSS-9021066 and CMS-9402563, the U.S. Department of Transportation - Federal Highway Administration, the Reinforced Concrete Research Council under RCRC Project 56, ABC Coating, Inc., Birmingham Steel Corporation, Chaparral Steel Company, Fletcher Coating Company, Florida Steel Corporation, Morton Powder Coatings, Inc., North Star Steel Company, O'J3iien Powder Products, Inc., and 3M Corporation. Support was also provided by Geiger Rcady-Msir, Iron Mountain Trap Rock Company, and Richmond Screw Anchor Company. 


\section{INTRODUCTION}

Recent work to improve the development characteristics of reinforcing bars by modifying bar deformation patterns (Darwin and Graham 1993a, 1993b, Darwin, Tholen, Idun and Zuo 1995a) has included a reevaluation of existing development and splice tests and the formulation of an expression to represent the bond force of bottom-cast bars at development/splice failure (Darwin, Zuo, Tholen, and Idun 1995b).

Based on this analysis, the best-fit equation for the ultimate bond force, $T_{b}$, is

$$
\begin{gathered}
\frac{T_{b}}{f_{c}^{\prime 1 / 4}}=\frac{A_{b} f_{s}}{f_{c}^{\prime 1 / 4}}=\left[63 l_{d}\left(c_{m}+0.5 d_{b}\right)+2130 A_{b}\right]\left(0.1 \frac{c_{M}}{c_{m}}+0.9\right) \\
+2226 t_{r} t_{d} \frac{N A_{t r}}{n}+66
\end{gathered}
$$

in which $\mathrm{T}_{\mathrm{b}} \quad=$ force in bar at development or splice failure, in $\mathrm{lb}$

$A_{b}=$ bar area, in in.2

$\mathrm{d}_{\mathrm{b}} \quad=$ nominal bar diameter, in in.

$\mathrm{f}_{\mathrm{s}} \quad=$ steel stress at failure, in psi

$f_{c}^{\prime} \quad=$ concrete compressive strength, in psi; $f_{c}^{\prime 1 / 4}$ in psi

$l_{d}=$ development or splice length, in in.

$c_{m}, c_{M}=$ minimum or maximum value of $c_{s}$ or $c_{b}\left(c_{M} / c_{m} \leq 3.5\right)$, in in.

$\mathrm{c}_{\mathrm{s}}=\min \left(\mathrm{c}_{\mathrm{si}}+0.25 \mathrm{in} ., \mathrm{c}_{\mathrm{so}}\right)$, in in.

$\mathrm{c}_{\mathrm{si}}=$ one-half of clear spacing between bars, in in.

$c_{s o}, c_{b}=$ side cover or bottom cover of reinforcing bars, in in.

$\mathrm{N} \quad=$ number of transverse reinforcing bars (stirrup or ties) crossing $l_{d}$

$\mathrm{A}_{\mathrm{tr}} \quad=$ area of transverse reinforcement crossing the potential plane of spliting adjacent to the reinforcement being developed, in in. 2

$\mathrm{n} \quad=$ number of bars being developed or spliced along the plane of splitting 


$$
\begin{aligned}
t_{\mathrm{x}}= & 9.6 \mathrm{R}_{\mathrm{r}}+0.28 \\
\mathrm{t}_{\mathrm{d}}= & 0.72 \mathrm{~d}_{\mathrm{b}}+0.28 \\
\mathrm{R}_{\mathrm{r}}= & \text { ratio of projected rib area normal to bar axis to the product of the nominal bar } \\
& \text { perimeter and the center-to-center rib spacing }
\end{aligned}
$$

The final term in Eq. 1, 66, is used only if the member has confining transverse reinforcement.

Eq. 1 is based on the analysis of 133 development and splice tests of bottom-cast bars without confining reinforcement and 166 tests with confining reinforcement (Chinn et al. 1955, Chamberlin 1956, 1958, Mathey and Watstein 1961, Ferguson and Thompson 1965, Ferguson and Breen 1965, Thompson et al. 1975, Zekany et al. 1981, Choi et al. 1990, 1991, DeVries et al. 1991, Hester et al. 1991, 1993, Rezansoff et al. 1991, 1993, Azizinamini et al. 1993, 1995, Darwin et al. 1995a). The data base includes specimens with concrete strengths, $\mathrm{f}_{\mathrm{c}}^{\prime}$, between 1820 and $15,760 \mathrm{psi}\left(13\right.$ and $109 \mathrm{MPa}$ ) and bars with relative rib areas, $\mathrm{R}_{\mathrm{r}}$, between 0.056 and 0.140 ; the relative rib area has been shown to significantly affect the contribution of transverse reinforcement to bond strength (Darwin and Graham 1993a, 1993b, Darwin et al. 1995a). The effect of $R_{t}$ is reflected in the expression for $t_{r} . R_{r}$ averages 0.0727 for conventional reinforcement and 0.1275 for newly proposed high relative rib area bars (Darwin et al. 1995a, 1995b).

Eq. 1 produces a mean test/prediction ratio of 1.00 , with a coefficient of variation, $V_{T / P}$, of 0.107 for beams in which the bars are not confined by transverse reinforcement and a mean test/prediction ratio of 1.01 , with $\mathrm{V}_{\mathrm{T} / \mathrm{P}}=0.125$, for beams in which the bars are confined by transverse reinforcement.

Eq. 1 can be used to calculate development/splice length, $1_{d}$, by dropping the final term, 66 , and setting $\mathrm{N}=1_{\mathrm{d}} / \mathrm{s}$, in which $\mathrm{s}=$ spacing of transverse reinforcement, in in.

$$
\frac{\mathrm{l}_{\mathrm{d}}}{\mathrm{d}_{\mathrm{b}}}=\frac{\frac{\mathrm{f}_{\mathrm{s}}}{\mathrm{f}_{\mathrm{c}}^{\prime 1 / 4}}-2130\left(0.1 \frac{\mathrm{c}_{\mathrm{M}}}{\mathrm{c}_{\mathrm{m}}}+0.9\right)}{80.2\left(\frac{\mathrm{c}+\mathrm{K}_{\mathrm{tr}}}{\mathrm{d}_{\mathrm{b}}}\right)}
$$


in which $c=\left(c_{m}+0.5 d_{b}\right)\left(0.1 c_{M} / c_{m}+0.9\right), K_{t r}=35.3 t_{r} t_{d} A_{u} / s n$, and $\left(c+K_{t r}\right) / d_{b} \leq 4.0$

Eq. 2 can be further simplified by setting $\mathrm{c}_{\mathrm{M}} / \mathrm{c}_{\mathrm{m}}=1$ and dropping 0.25 in. from the defini. tion of $c_{s}$.

$$
\frac{1_{d}}{d_{b}}=\frac{\frac{f_{s}}{f_{c}^{\prime 1 / 4}}-2130}{80.2\left(\frac{c+K_{t r}}{d_{b}}\right)}
$$

in which $c=\left(c_{m}+0.5 d_{b}\right)$.

Converting Eqs. 2 and 3 back to a form that can be used to predict $T_{b}=A_{b} f_{s}$ gives, respec. tively,

$$
\begin{aligned}
& T_{b}=A_{b} f_{s}=f_{c}^{\prime 1 / 4}\left\{\left[631_{d}\left(c_{m}+0.5 d_{b}\right)+2130 A_{b}\right]\left(0.1 \frac{c_{M}}{c_{m}}+0.9\right)\right. \\
& \left.+2226 t_{r} t_{d} \frac{l_{d} A_{t r}}{s n}\right\} \\
& T_{b}=A_{b} f_{s}=f_{c}^{\prime 1 / 4}\left\{\left[631_{d}\left(c_{m}+0.5 d_{b}\right)+2130 A_{b}\right]+2226 t_{r} t_{d} \frac{l_{d} A_{t r}}{s n}\right\}
\end{aligned}
$$

in which $t_{r}=0.98$ for conventional bars and 1.50 for high relative rib area bars, and $c_{s}$ (used to determine $c_{m}$ ), is defined appropriately in the two expressions.

Eq. 4 (and Eq. 2) represents, very nearly, the best-fit equation for the full data base, Eq. 1 . Therefore, 50 percent of the development/splice designs based on this expression will be weaker than predicted by Eq. 1 - a situation that presents unacceptable safety risks. Eq. 5 (and Eq. 3) is, in general, more conservative than Eq. 4, but will provide the same value of $1_{d}$ as Eq. 4 when $\mathrm{c}_{\mathrm{m}}=$ $c_{b}=c_{s o}$. 
The level of safety can be improved by reducing the usable bond force, $T_{b}=A_{b} f_{s}$, by multiplying the right side of Eqs. 4 and 5 by a suitable strength reduction ( $\phi)$ factor. A longer development length is then required to provide the desired value of $T_{b}$.

This report describes the calculation of a reliability-based $\phi$-factor for developed and spliced bars with relative rib areas of 0.0727 and 0.1275 (for conventional and high relative rib area bars, respectively). Bars both with and without confining transverse reinforcement are considered. The $\phi$-factor is used in conjunction with Eqs. 4 and 5 to formulate design expressions for $1_{d}$ that are similar in format to Eqs. 2 and 3. The overall approach is described first, followed by the details of the calculation. As will be demonstrated, a major advantage of the final expressions is that they provide identical values for development and splice length.

\section{CALCULATION OF STRENGTH REDUCTION FACTORS}

\section{Overall Approach}

The capacity reduction factor, $\phi_{\mathrm{b}}$, must be selected to insure an acceptably low probability of bond failure. Considering the brittle nature of bond failures, that probability should be lower than the probability of failure under a main load-carrying mechanism, such as bending or combined bending and compression. This can be achieved by using the concepts of structural reliability.

Limiting consideration to "statically" applied load for the purpose of this analysis (i.e., not seismic or shock loading), it is recognized that the bar force, $A_{b} f_{s}$, that appears on the left side of Eqs. 4 and 5 has already been increased by a factor of $1 / \phi$, in which $\phi=$ strength reduction factor for the main loading, before development/splice design is undertaken. So as not to double-count $\phi$-factors, the resistance to which $\phi_{\mathrm{b}}$ is applied corresponds to $\phi \mathrm{A}_{\mathrm{b}} \mathrm{f}_{\mathrm{s}}$ (equivalent to the factored load). That is,

$\phi A_{b} f_{s} \geq \phi_{b}$ [Right side of Eq. 4 or 5] 
Therefore, the effective $\phi$-factor for use in calculating development/splice length becomes $\phi_{d}=$ $\phi_{\mathrm{b}} / \phi$, although the overall $\phi$-factor against bond failure remains $\phi_{\mathrm{b}}$.

$$
A_{b} f_{s} \geq \phi_{d}[\text { Right side of Eq. } 4 \text { or 5] }
$$

Determining the value of $\phi_{\mathrm{b}}$ (and ultimately $\phi_{\mathrm{d}}$ ) requires the selection of the desired level of reliability, which can be represented by the reliability index, $\beta$ (Ellingwood, Galambos, MacGregor, and Cornell 1980). For a resistance, $\mathrm{R}$, and a loading, $\mathrm{Q}$, failure will not occur if $\mathrm{R} / \mathrm{Q} \geqslant$ 1. Using the formulation shown in Fig. 1 and the small-variance approximations (Ellingwood et al. 1980), $\overline{\ln (\mathrm{R} / \mathrm{Q})} \approx \ln (\overline{\mathrm{R}} / \overline{\mathrm{Q}})$ and $\sigma_{\ln (\mathrm{R} / \mathrm{Q})} \propto\left(\mathrm{V}_{\mathrm{R}}^{2}+\mathrm{V}_{\mathrm{Q}}^{2}\right)^{1 / 2}$, in which the overbar represents the average, $\sigma=$ standard deviation, and $V=$ coefficient of variation,

$$
\beta=\frac{\overline{\ln (\mathrm{R} / \mathrm{Q})}}{\sigma_{\ln (\mathrm{R} / \mathrm{Q})}} \propto \frac{\ln (\overline{\mathrm{R}} / \overline{\mathrm{Q}})}{\left(\mathrm{V}_{\mathrm{R}}^{2}+\mathrm{V}_{\mathrm{Q}}^{2}\right)^{1 / 2}}
$$

Under typical conditions of loading, $\beta \approx 3.0$ for reinforced concrete beams and columns (Ellingwood et al. 1980). A higher value of $\beta$ is needed to insure that the probability of a bond failure is lower than the probability of a failure in bending for beams or in combined bending and compression for columns. Therefore, $\beta=3.5$ is used in the calculation of development/splice length, producing a probability of failure equal to approximately one-fifth of that obtained with $\beta=$ 3.0 .

Eq. 8 can be used to calculate $\phi_{b}$, but to do so requires knowledge of $R$ and $Q$, both of which are random variables. This knowledge can be obtained through the application of Monte Carlo analysis, used in conjunction with data obtained from field measurements and test results. The derivation that follows parallels techniques used by Ellingwood et al. (1980), Mirza and MacGregor (1986), and Lundberg (1993):

$\mathrm{R}=$ random variable for resistance, which is represented as 
$R=X(1) R_{p}$

in which $X(1)=$ test-to-predicted load capacity random variable

$R_{p}=$ predicted capacity random variable, dependent on material and geometric properties of member, which are also random variables

$\mathrm{Q}=\Sigma$ loads

For dead load and live load,

$$
\begin{aligned}
& \mathrm{Q}=\mathrm{Q}_{\mathrm{D}}+\mathrm{Q}_{\mathrm{L}} \\
& \mathrm{Q}=\left(\frac{\mathrm{Q}_{\mathrm{D}}}{\mathrm{Q}_{\mathrm{Dn}}}+\frac{\mathrm{Q}_{\mathrm{L}}}{\mathrm{Q}_{\mathrm{Dn}}}\right) \mathrm{Q}_{\mathrm{Dn}}
\end{aligned}
$$

in which $\mathrm{Q}_{D}$ and $\mathrm{Q}_{\mathrm{L}}=$ random variables representing dead and live load effects

$$
\begin{aligned}
\mathrm{QDn}_{\mathrm{n}} & =\text { nominal dead load } \\
\frac{\mathrm{Q}_{\mathrm{D}}}{\mathrm{Q}_{\mathrm{Dn}}} & =\mathrm{X}(2) \\
\frac{\mathrm{Q}_{\mathrm{L}}}{\mathrm{Q}_{\mathrm{Dn}}} & =\frac{\mathrm{Q}_{\mathrm{L}}}{\mathrm{Q}_{\mathrm{Ln}}} \frac{\mathrm{Q}_{\mathrm{Ln}}}{\mathrm{Q}_{\mathrm{Dn}}}=\mathrm{X}(3)\left(\frac{\mathrm{Q}_{\mathrm{L}}}{\mathrm{Q}_{\mathrm{D}}}\right)_{n}
\end{aligned}
$$

in which $\mathrm{Q}_{\mathrm{Ln}} \quad$ = nominal live load

$X(2), X(3)=$ actual-to-nominal dead and live load random variables

$\left(\frac{Q_{L}}{Q_{D}}\right)_{n}=$ nominal ratio of live load to dead load 
In design,

$$
\phi_{\mathrm{C}} \mathrm{R}_{\mathrm{n}}=\gamma_{\mathrm{D}} \mathrm{Q}_{\mathrm{Dn}}+\gamma_{\mathrm{L}} \mathrm{Q}_{\mathrm{Ln}}
$$

in which $\phi_{c}=$ "composite" strength reduction factor (for this derivation, $\phi_{c}=\phi_{b}$ )

$\mathbf{R}_{\mathbf{n}} \quad=$ nominal resistance

$\gamma_{\mathrm{D}}, \gamma_{\mathrm{L}}=$ load factors for dead and live loads

Factoring out $\mathrm{Q}_{D_{n}}$ on the right side of Eq. 15 and setting $\mathrm{Q}_{L} / \mathrm{QDn}_{\mathrm{n}}=\left(\mathrm{Q}_{\mathrm{J}} / \mathrm{Q}_{\mathrm{D}}\right)_{\mathrm{n}}$ gives

$$
\phi_{c} R_{n}=Q_{D n}\left[\gamma_{D}+\gamma_{L}\left(\frac{Q_{L}}{Q_{D}}\right)_{n}\right]
$$

Solving Eq. 16 for $\mathrm{Q}_{\mathrm{Dn}}$ gives

$$
\mathrm{Q}_{\mathrm{Dn}}=\frac{\phi_{c} \mathrm{R}_{\mathrm{n}}}{\gamma_{\mathrm{D}}+\gamma_{\mathrm{L}}\left(\frac{\mathrm{Q}_{\mathrm{L}}}{\mathrm{Q}_{\mathrm{D}}}\right)_{\mathrm{n}}}
$$

The total load, Q, is obtained by substituting Eqs. 13, 14, and 17 into Eq. 12.

$$
\mathrm{Q}=\frac{\left[X(2)+X(3)\left(\frac{Q_{L}}{Q_{D}}\right)_{n}\right] \phi_{c} R_{n}}{\gamma_{D}+\gamma_{L}\left(\frac{Q_{L}}{Q_{D}}\right)_{n}}
$$

Letting

$$
q=\frac{\left[X(2)+X(3)\left(\frac{Q_{L}}{Q_{D}}\right)_{n}\right]}{\gamma_{D}+\gamma_{L}\left(\frac{Q_{L}}{Q_{D}}\right)_{n}}
$$


$\mathrm{Q}=\phi_{\mathrm{c}} q \mathrm{R}_{\mathrm{n}}$

Defining $r=\frac{R}{R_{n}}=\frac{X(1) R_{p}}{R_{n}}$

$R=X(1) R_{p}=r R_{n}$

From Eq. 8,

$$
\begin{aligned}
\beta=\frac{\overline{\ln (R / Q)}}{\sigma_{\ln (R / Q)}}=\frac{\overline{\ln \left(r R_{n} / \phi_{c} q R_{n}\right)}}{\sigma_{\ln \left(r R_{n} / \phi_{c} q R_{n}\right)}}=\frac{\overline{\ln \left(r / \phi_{c} q\right)}}{\sigma_{\ln \left(r / \phi_{c} q\right)}} \\
=\frac{\ln \left(\bar{r} / \overline{\left.\phi_{c} q\right)}\right.}{\left(V_{r}^{2}+V_{\phi q}^{2}\right)^{1 / 2}}=\frac{\ln \left(\bar{r} / \phi_{c} \bar{q}\right)}{\left(V_{r}^{2}+V_{\phi q}^{2}\right)^{1 / 2}}
\end{aligned}
$$

in which

$$
\begin{aligned}
& \bar{r}=\overline{\left(\frac{X(1) R_{p}}{R_{n}}\right)} \\
& V_{r}=\frac{\sigma_{r}}{\bar{r}} \\
& \bar{q}=\frac{X(2)+X(3)\left(\frac{Q_{L}}{Q_{D}}\right)_{n}}{\gamma_{D}+\gamma_{L}\left(\frac{Q_{L}}{Q_{D}}\right)_{n}}
\end{aligned}
$$




$$
\mathrm{V}_{\phi \mathrm{q}}=\frac{\phi_{c} \sigma_{\mathrm{q}}}{\phi_{\mathrm{c}} \overline{\mathrm{q}}}=\frac{\sigma_{\mathrm{q}}}{\overline{\mathrm{q}}}=\frac{\left\{\left[\overline{\mathrm{X}(2)} \mathrm{V}_{\mathrm{Q}_{\mathrm{D}}}\right]^{2}+\left[\overline{\mathrm{X}(3)}\left(\frac{\mathrm{Q}_{\mathrm{L}}}{\mathrm{Q}_{\mathrm{D}}}\right)_{\mathrm{n}} \mathrm{V}_{\mathrm{Q}_{\mathrm{L}}}\right]^{2}\right\}^{1 / 2}}{\overline{\mathrm{X}(2)}+\overline{\mathrm{X}(3)}\left(\frac{\mathrm{Q}_{\mathrm{L}}}{\mathrm{Q}_{\mathrm{D}}}\right)_{\mathrm{n}}}
$$

$\phi_{c}$ is calculated using Eq. 22. Starting with $\beta=\left[\ln \left(\bar{r} / \phi_{c} \bar{q}\right)\right] /\left(V_{r}^{2}+V_{\phi q}^{2}\right)^{1 / 2}$,

$$
\begin{aligned}
& \left(V_{r}^{2}+V_{\phi q}^{2}\right)^{1 / 2} \beta=\ln \left(\frac{\bar{r}}{\phi_{c} \bar{q}}\right) \\
& e^{\left(V_{r}^{2}+V_{\phi q}^{2}\right)^{1 / 2 \beta}}=\frac{\bar{r}}{\phi_{c} \bar{q}} \\
& \phi_{c}=\frac{\bar{r}}{\bar{q}} e^{-\left(V_{r}^{2}+V_{\phi q}^{2}\right)^{1 / 2} \beta}
\end{aligned}
$$

\section{Random Variables}

The mean values, $\bar{r}$ and $\bar{q}$, and the coefficients of variation, $V_{r}$ and $V_{\phi q}$, are needed to calculate $\phi_{c}$ using Eq. 29. The values associated with the resistance random variable $r, \bar{r}$ and $V_{r}$, are obtained first, followed by the values associated with the load random variable $q, \bar{q}$ and $V_{\phi q}$.

Resistance Random Variable-Resistance random variable $\mathrm{r}$ is obtained using Eq. 21a.

$$
r=\frac{R}{R_{n}}=\frac{X(1) R_{p}}{R_{n}}
$$

Test-to-predicted load random variable, $X(1)$. The test-to-predicted load random variable, $\mathrm{X}(1)$, is based on a comparison of test results with Eq. 1. $\mathrm{X}(1)$ is treated as a normal random 
variable with a mean equal to the mean test/prediction ratio. $\overline{\mathrm{X}(1)}=1.00$ and 1.01 for members without and with confining transverse reinforcement, respectively (Darwin et al. 1995b). The coefficient of variation $V_{X(1)}$ is equal to the coefficient of variation associated with the predictive equation (or model) itself, $\mathrm{V}_{\mathrm{m}}$, as separate from uncertainties in the measured loads and differences in the actual material and geometric properties of the specimens from values used to calculate the predicted strength, represented by $V_{t s .}$. The total coefficient of variation in the test/prediction ratio, $\mathrm{V}_{\mathrm{T} / \mathrm{P}}$, is equal to $\left(\mathrm{V}_{\mathrm{m}}{ }^{2}+\mathrm{V}_{\mathrm{ts}}\right)^{1 / 2}$ (Grant, Mirza, and MacGregor 1978). Therefore, $\mathrm{V}_{\mathrm{m}}=\left(\mathrm{V}_{\mathrm{T} / \mathrm{P}^{2}-}\right.$ $\left.\mathrm{V}_{\mathrm{ts}^{2}}\right)^{1 / 2}$.

For reinforced concrete, $\mathrm{V}_{\mathrm{ts}} \approx 0.07$ (Grant et al. 1978). For beams without confining reinforcement, $\mathrm{V}_{\mathrm{m}}=\left(\mathrm{V}_{\mathrm{T} / \mathrm{P}^{2}}-\mathrm{V}_{\mathrm{ts}}\right)^{1 / 2}=\left(0.107^{2}-0.072\right)^{1 / 2}=0.081$. For beams with confining reinforcement, additional uncertainty occurs because the relative rib area, $R_{r}$, is not known for 34 of the beams used to establish Eq. 1. This is handled with $V_{R_{r}}=0.02$, giving $V_{m}=\left(V_{T / P^{2}}-V_{t s}{ }^{2}\right.$ $\left.-\mathrm{V}_{\mathrm{R}_{\mathrm{r}}}^{2}\right)^{1 / 2}=\left(0.125^{2}-0.072-0.02^{2}\right)^{1 / 2}=0.102$.

Predicted Capacity Random Variable, $R_{p}$. The individual values of the predicted capacity random variable, $R_{p}$, are obtained for hypothetical beams using the Monte Carlo method. The random variables used to calculate $R_{p}$ are the concrete strength, $f_{c}^{\prime}$ (adjusted for the rate of loading), the development/splice length, $l_{d}$ the member width, $b$, the cover, $c_{b}$, the side cover, $c_{s o}$, and the relative rib area of the developed/spliced bar, $R_{r}$. The predicted capacity, $R_{p}$, is calculated by solving Eq. 1 for $\mathrm{A}_{\mathrm{b}} \mathrm{f}_{\mathrm{s}}$.

$$
\begin{aligned}
\mathrm{R}_{\mathrm{p}}=\mathrm{A}_{\mathrm{b}} \mathrm{f}_{\mathrm{s}}= & \mathrm{f}_{\mathrm{c}}^{\prime 1 / 4}\left\{\left[63 \mathrm{l}_{\mathrm{d}}\left(\mathrm{c}_{\mathrm{m}}+0.5 \mathrm{~d}_{\mathrm{b}}\right)+2130 \mathrm{~A}_{\mathrm{b}}\right]\left(0.1 \frac{\mathrm{c}_{\mathrm{M}}}{\mathrm{c}_{\mathrm{m}}}+0.9\right)\right. \\
& \left.+2226 \mathrm{t}_{\mathrm{r}} \mathrm{t}_{\mathrm{d}} \frac{\mathrm{NA} \mathrm{A}_{\mathrm{tr}}}{\mathrm{n}}+66\right\}
\end{aligned}
$$

Individual values of $R_{p}$ are calculated by substituting values for each of the variables that are determined based on the nominal value and statistical properties of that variable. Beams with 
spliced bars are used as the physical model in this study.

Concrete strength, $f_{c}^{\prime}[X(4)]$. The random variable for concrete strength, $X(4)$, must take into consideration the strength and variability of concrete, as used in practice, and the effect of the actual load rate in the structure, as opposed to the load rate used in standard tests (Mirza, Hatzinikolas, and MacGregor 1979). The latter point is considered first.

A relation proposed by Jones and Richart (1936) is used to take into account the fact that, under practical conditions, loading rates will be different than the average value of $35 \mathrm{psi} / \mathrm{sec}(0.24$ $\mathrm{MPa} / \mathrm{sec}$ ) used in a standard compression test (ASTM C 39).

$$
f_{c f}^{\prime}=0.89 f_{c 35}^{\prime}(1+0.08 \log f)
$$

in which $0.1 \mathrm{psi} / \mathrm{sec} \leq \mathrm{f} \leq 10,000 \mathrm{psi} / \mathrm{sec}$

$$
\begin{aligned}
& f_{c{ }^{\prime}}^{\prime}=\text { compressive strength of concrete at stress rate } \mathrm{f} \\
& \mathrm{f}_{\mathrm{c} 35}^{\prime}=\text { compressive strength of concrete at } \mathrm{f}=35 \mathrm{psi} / \mathrm{sec}(0.24 \mathrm{MPa} / \mathrm{sec})
\end{aligned}
$$

It is assumed that, in practice, the load rate will be such that failure will occur in one hour, resulting in a lower effective compressive strength than would be obtained in a standard test. The stress rate, $\mathfrak{f}$, corresponding to compressive failure in one hour is

$$
f=\frac{f_{c f}^{\prime}}{3600}
$$

The values of $f$ and $f_{c f}^{\prime}$ are obtained by iteration using Eqs. 31 and 32 .

The selection of the value of $\mathrm{f}_{\mathrm{c} 35}^{\prime}$, which should be representative of concrete strength in the field, is affected by two considerations: 1) Splice tests are calibrated against the compressive strength of standard cylinders that are cured in the same manner as the splice test specimens, not on the actual strength of the concrete in the splice specimens. The closest thing in concrete construc- 
tion is the use of field-cured specimens. 2) In practice, concrete must be proportioned to produce a higher strength than used to design the structure to insure that the strength of most of the concrete will exceed the specified value of $f_{c}^{\prime}$.

The two considerations have opposite effects on the value of $f_{c 35}^{\prime}$ used in the analysis, since field-cured cylinders usually produce a lower strength than standard laboratory-cured specimens (the basis upon which $f_{c}^{\prime}$ is measured), while the average strength of concrete produced in the field, as measured using standard specimens, exceeds $\mathrm{f}_{c}^{\prime}$ by a considerable amount. These opposing effects largely cancel each other out. Therefore, the specified value of $\mathrm{f}_{c}^{\prime}$ is used as the mean value of the concrete strength for use in determining $R_{p}$.

$$
\mathrm{f}_{\mathrm{c} 35}^{\prime}=\mathrm{f}_{\mathrm{c}}^{\prime}
$$

$f_{c}^{\prime}$ in Eq. 30 is replaced by the normally distributed random variable $X(4)$ with a mean value $\overline{X(4)}=f_{c \dot{f}}^{\prime}$ [Eqs. 31 and 32]. For ${f^{\prime}}_{c}=4000$ psi $(28 \mathrm{MPa}), \overline{X(4)}=f_{c f}^{\prime}=3559$ psi $(24.54$ $\mathrm{MPa}$ ). The standard deviation $\sigma_{\mathrm{X}(4)}=\mathrm{V}_{\mathrm{c}} \mathrm{f}_{\mathrm{cf}}^{\prime}$ is based on 1) an assumed standard deviation for standard laboratory cylinders, $\sigma_{c c y l}=550 \mathrm{psi}(3.8 \mathrm{MPa})$, representative of good job-site quality control, and 2) an assumed variability for in-place concrete, expressed as $V_{c}=\left(V_{c c y l}{ }^{2}+0.0\right.$ 084)1/2 (Mirza et al. 1979), in which $V_{c c y l}=\sigma_{c c y l} / f_{c r}^{\prime}$ and $f_{c r}^{\prime}=$ required average compressive strength of concrete $={f^{\prime}}_{c}+2.33 \sigma_{c c y l}-500$ psi (Eq. 5-2 of ACI 318-89). For ${f^{\prime}}_{c}=4000$ psi (28 $\mathrm{MPa}), \mathrm{V}_{\mathrm{c}}=0.147$ and $\sigma_{\mathrm{X}(4)}=523 \mathrm{psi}(3.6 \mathrm{MPa})$.

Geometric Properties. The balance of the random variables used to calculate $R_{p}$ are the geometric properties of the structural member and the reinforcement. The tolerances in ACI 11790 are used as the basis for establishing the variability of the geometric properties of concrete sections. All geometric properties are represented using normal distributions.

The splice length, $1_{d}$, is represented by the random variable $X(5)$, with a mean equal to the 
specified value of $l_{d}$. The tolerance for the embedded length of bars and the length of bar laps in ACI $117-90$ is -1 in. ( $25 \mathrm{~mm})$ for No. 3 through No. 11 (9.5 through $36 \mathrm{~mm})$ bars. It is assumed that 95 percent of all bars will meet this criterion. For the normal distribution $\mathrm{X}(5)$, this means that $1.645 \sigma_{X(5)}=1 \mathrm{in.}(25 \mathrm{~mm})$, or $\sigma_{X(5)}=0.61 \mathrm{in} .(16 \mathrm{~mm})$. [The values of $\sigma_{X(i)}$ are shown rounded to two significant figures. No rounding, however, is used in the calculation of $\phi$.]

Concrete cover, $\mathrm{c}_{\mathrm{b}}$, is represented by random variable $\mathrm{X}(6)$, with a mean equal to the specified cover. The tolerance on cover in ACI 117-90 is - $3 / 8$ in. $(9.5 \mathrm{~mm}$ ) for members less than or equal to $12 \mathrm{in}$. (305 mm) in size and $-1 / 2 \mathrm{in}$. $(13 \mathrm{~mm}$ ) for members greater than $12 \mathrm{in.}$ (305 $\mathrm{mm})$ in size. Again, assuming that 95 percent of all members will meet these criteria, $1.645 \sigma_{\mathrm{X}(6)}$ $=0.375$ in. $(9.5 \mathrm{~mm})$, or $\sigma_{X(6)}=0.23$ in. $(6 \mathrm{~mm})$ for members $\leq 12$ in. $(305 \mathrm{~mm})$ in size, and $1.645 \sigma_{\mathrm{X}(6)}=0.5 \mathrm{in} .(13 \mathrm{~mm})$, or $\sigma_{\mathrm{X}(6)}=0.30 \mathrm{in} .(8 \mathrm{~mm})$ for members $>12 \mathrm{in} .(305 \mathrm{~mm})$ in size.

Side cover, $c_{s o}$, is represented by random variable $X(7)$, with a mean equal to the specified value of $c_{s o}$. In this case, the tolerances on placement of reinforcement in $\mathrm{ACl} 117-90$ are $\pm 3 / 8$ in. ( $9.5 \mathrm{~mm}$ ) for members between 4 and $12 \mathrm{in.} \mathrm{(102} \mathrm{and} 305 \mathrm{~mm}$ ) in size and $\pm 1 / 2$ in. (13 mm) for members greater than $12 \mathrm{in.} \mathrm{(305} \mathrm{mm)} \mathrm{in} \mathrm{size.} \mathrm{Since} \mathrm{c}_{\mathrm{so}}$ is bounded on two sides, if 95 percent of all bar placements meet these criteria, the tolerances are equal to $1.96 \sigma_{\mathbf{X}(7)}$. Using procedures similar to those used for $c_{b}$ and $l_{d}, \sigma_{X(7)}=0.19$ in. for members between 4 and $12 \mathrm{in.}$ (102 and $305 \mathrm{~mm})$ in size and $\sigma_{X(7)}=0.26 \mathrm{in}$. (7 mm) for members $>12 \mathrm{in} .(305 \mathrm{~mm})$ in size.

One-half of the clear spacing between bars, $\mathrm{c}_{\mathrm{si}}$, is calculated as

$$
c_{s i}=\frac{b-2 n_{b} d_{b}-2 c_{s o}}{2\left(n_{b}-1\right)}
$$

in which $n_{b}=$ number of bars. In this expression, in addition to $c_{s o}$, beam width, $b$, is a random variable, represented by $X(8)$.

The tolerances on cross-sectional dimensions in ACI 117-90 are $+3 / 8$ in. and $-1 / 4$ in. 
$(+9.5 \mathrm{~mm}$ and $-6.5 \mathrm{~mm})$ for members with dimensions of $12 \mathrm{in}$. $(305 \mathrm{~mm})$ or less and $+1 / 2$ in. and $-3 / 8$ in. ( $+13 \mathrm{~mm}$ and $-9.5 \mathrm{~mm}$ ) for members with dimensions greater than $12 \mathrm{in}$. ( $305 \mathrm{~mm}$ ), but less than $3 \mathrm{ft}(914 \mathrm{~mm})$. ACI 117-90 also provides criteria for members over $3 \mathrm{ft}(914 \mathrm{~mm})$ in dimension, but these are not used in the current Monte Carlo analysis. The mean value of beam width, $\overline{\mathrm{X}(8)}$, is taken as the nominal beam width plus the average of the tolerances $=b+0.0625$ in. $(1.6 \mathrm{~mm})$ for members in both size categories. The standard deviations are selected such that 95 percent of all members have dimensions between the tolerances, giving $\sigma_{\mathrm{X}(8)}=0.16 \mathrm{in}$. $(4 \mathrm{~mm}$ ) for members with $b \leq 12 \mathrm{in}$. (305 mm) and $\sigma_{X(8)}=0.22 \mathrm{in}$. $(6 \mathrm{~mm})$ for members $12<b \leq 36$ in. $(305<\mathrm{b} \leq 914 \mathrm{~mm})$.

The term representing the effect of relative rib area on the effectiveness of transverse reinforcement on bond strength, $t_{\mathrm{r}}=9.6 \mathrm{R}_{\mathrm{r}}+0.28$, depends on the random variable representing $R_{r}=X(9) . \quad \bar{R}_{x}=\overline{X(9)}=0.0727$ for conventional reinforcement and 0.1275 for high relative rib area reinforcement. Conservatively, the standard deviations are $\sigma_{\mathrm{X}(9)}=0.0090$ for conventional reinforcement and 0.0045 for high relative rib area reinforcement (Darwin et al. 1995b).

In Eqs. 4 and 5, the number of stirrups crossing the splice, N, (Eqs. 1 and 30) has been replaced by $l_{d} / s$. $N$, of course, must have an integer value, although $l_{d} / s$ is the value used in Eqs. 2 and 3 to calculate development and splice length. As an example, if $l_{d} / s=3.6$, the development/ splice length would be crossed by four stirrups 60 percent of the time and three stirnups 40 percent of the time, for an average of 3.6 stirrups. Thus, the average strength can be based on 3.6 stirrups. However, using 3.6 stirrups does not account for the variability in strength that occurs because some splices are crossed by 3 stirrups, while others are crossed by 4 . This variability is accounted for in the Monte Carlo simulation by applying the appropriate weights to the calculated strengths for the two integer values for the number of stirrups. This results in a lower $\phi$-factor than if $N=l_{d} / s$ were used to calculate $R_{p}$.

Nominal Strength, $R_{n}$. The nominal strength, $R_{n}$, is calculated using Eq. 4 or Eq. 5 with 
the specified concrete strength, $f_{c}^{\prime}$, and the nominal dimensions of the member.

Monte Carlo Simulation. The values of $\overline{\mathrm{r}}$ and $\mathrm{V}_{\mathrm{r}}$ (Eq. 24) are obtained using Monte Carlo simulations of a selected number of beams. For each beam and simulation, values are selected for normally distributed random variables $X(1)$ and $X(4)-X(9)$. To do this for each variable, a random number between 0 and 1 is used with the cumulative distribution function to calculate the standard normal random variable, $z(-\infty<z<\infty)$. For variable $i, X(i)=\overline{X(i)}+z \sigma_{X(i)}$. The values of $\mathrm{X}(\mathrm{i})$ are used to calculate $\mathrm{r}$ (Eq. 21a) for the simulation. The results of multiple simulations are combined to obtain $\overline{\mathrm{r}}$ and $\mathrm{V}_{\mathrm{r}}$.

Loading Random Variable-The term q, given in Eq. 19, depends on random variables $X(2)$ and $X(3)$, representing the actual-to-nominal ratios for dead and live load, respectively; load factors for dead and live load, $\gamma_{D}$ and $\gamma_{L}$; and the nominal live load-to-dead load ratio, $\left(Q_{L} / Q_{D}\right)_{n}$. $\gamma_{\mathrm{D}}$ and $\gamma_{\mathrm{L}}$ are selected based on the load factors used in design, 1.4 and 1.7 for ACI 318-89, $\mathrm{ACI}$ 318-95, and AASHTO Highway (1992), and 1.2 and 1.6 for ASCE 7-93. Values of $\left(Q_{\nu} / Q_{D}\right)_{n}$ of $0.5,1.0$, and 1.5 are normally selected for evaluating the reliability of reinforced concrete structures, with a nominal live load-to-dead load ratio of 1.0 serving as the standard for calculating $\phi$ factors or determining the reliability index, $\beta$.

For reinforced concrete structures, $\overline{\mathrm{X}(2)}=\overline{\mathrm{Q}}_{\mathrm{D}} / \mathrm{Q}_{\mathrm{Dn}}=1.03$ and $\mathrm{V}_{\mathrm{Q}_{\mathrm{D}}}=0.093$ (Ellingwood et al. 1980). $X(3)=Q_{\nu} / Q_{L n}$ depends on the tributary area, $A_{T}$, and the influence area, $A_{I}$ (Ellingwood et al. 1980). For $A_{T}=400 \mathrm{ft}^{2}\left(37 \mathrm{~m}^{2}\right)$ and $A_{I}=800 \mathrm{ft}^{2}\left(74 \mathrm{~m}^{2}\right)$ (representative values for a reinforced concrete flexural member),

$$
\begin{aligned}
& \overline{\mathrm{Q}}_{\mathrm{L}}=\mathrm{L}_{\mathrm{o}}\left(0.25+\frac{15}{\sqrt{\mathrm{A}_{\mathrm{I}}}}\right)=0.780 \mathrm{~L}_{\mathrm{o}} \\
& \mathrm{Q}_{\mathrm{Ln}}=\mathrm{L}_{\mathrm{o}}\left\{1-\min \left[0.0008\left(\mathrm{~A}_{\mathrm{T}}-150\right), 0.6,0.23\left(1+\left(\frac{\mathrm{Q}_{\mathrm{D}}}{\mathrm{Q}_{\mathrm{L}}}\right)\right] \mathrm{n}\right)\right]=0.8 \mathrm{~L}_{\mathrm{o}}
\end{aligned}
$$


in which $\mathrm{L}_{\mathrm{o}}=$ basic (unreduced) live load and areas are in $\mathrm{ft}^{2}$.

Thus, $\overline{\mathrm{X}(3)}=\overline{\mathrm{Q}}_{\mathrm{L}} \mathrm{Q}_{\mathrm{Ln}}=0.975 . \mathrm{V}_{\mathrm{Q}_{\mathrm{L}}}=0.25$ (Ellingwood et al. 1980).

\section{STRENGTH REDUCTION FACTORS}

Strength reduction ( $\phi)$ factors are calculated for Eqs. 4 and 5 using 1) nominal live load-todead load ratios of $0.5,1.0$, and $1.5 ; 2$ ) two combinations of dead and live load factors - a) 1.4 and 1.7 (with $\phi$ for bending $=0.9$ ), and $b$ ) 1.2 and 1.6 (with $\phi$ for bending $=0.8$ ); 3) bars with relative rib areas of 0.0727 and 0.1275 ; and 4 ) members with and without confining transverse reinforcement.

The evaluations are based on splice lengths obtained from the respective equations calculated with a provisional value of $\phi_{d}=0.9$. [Note: The calculated $\phi$-factors are independent of the provisional value of $\phi_{\mathrm{d}}$.] Thirty-five beams in which the bars are not confined by transverse reinforcement and 140 beams (in four groups of 35 each) in which the bars are confined by transverse reinforcement are used in the calculations. The beams have widths of $8,12,18$, or $24 \mathrm{in}$. $(203,305,457$, and $610 \mathrm{~mm})$ and depths of 12 or $24 \mathrm{in.} \mathrm{(305} \mathrm{and} 610 \mathrm{~mm})$. Concrete strengths of 3000,4000 , and $6000 \mathrm{psi}(21,28$, and $41 \mathrm{MPa})$ are evaluated, and $2,4,6$, or 8 bars are spliced at the same location. No. 6 , No. 8 , No. 10 , and No. $11(19,25,32$, and $36 \mathrm{~mm})$ bars are used. For bars with confining transverse reinforcement, No. 3 and No. 4 (9.5 and $12.5 \mathrm{~mm}$ ) bar stirrups are spaced at values ranging from 4 to $10.8 \mathrm{in}$. (102 to $275 \mathrm{~mm}$ ). A summary of the beams used for the analysis is presented in Appendix A.

For each of the 35 beams without transverse reinforcement, 1000 Monte Carlo simulations are carried out in which the predicted strengths are calculated using Eq. 30 and the material and geometric random variables described in this report. For each of the 140 beams with transverse reinforcement, 250 simulations are carried out. The programs used for the Monte Carlo simula- 
tions are presented in Appendix B. The individual predicted strengths are used to calculate $\bar{r}$ (Eq. 23) and $V_{r}$ (Eq. 24). The selected load factors and live load-to-dead load ratios are used to calculate $\bar{q}$ (Eq. 25) and $V_{\phi q}$ (Eq. 26). The results are combined with $\beta=3.5$ to calculate $\phi_{c}=\phi_{b}$ (Eq. 29). The value of $\phi_{d}=\phi_{d} / \phi$ is then obtained.

The results of the Monte Carlo simulations are presented in Table 1.

Load factors 1.4 and 1.7-For Eq. 4, which is based on Eq. 2 (the more accurate of the two design equations), $\phi_{d}$ equals $0.94,0.91$, and 0.88 for bars without confining transverse reinforcement at live load-to-dead load ratios of $0.5,1.0$, and 1.5 , respectively; and $0.93,0.90$, and $0.88\left(R_{r}=0.0727\right)$ and $0.92,0.89$, and $0.87\left(R_{r}=0.1275\right)$ for bars with confining transverse reinforcement at the same live load-to-dead load ratios.

For Eq. 5, which is based on Eq. 3 (the more simplified of the two expressions), $\phi_{d}$ equals $0.89,0.87$, and 0.85 for bars without confining transverse reinforcement at live load-to-dead load ratios of $0.5,1.0$, and 1.5, respectively; and $0.99,0.97$, and $0.95\left(R_{r}=0.0727\right)$ and $0.97,0.95$, and $0.93\left(R_{\mathrm{r}}=0.1275\right)$ for bars with confining transverse reinforcement at the same live load-todead load ratios.

Load factors 1.2 and 1.6-For load factors of 1.2 and 1.6, the values of $\phi_{\mathrm{d}}$ increase slightly compared to those obtained for load factors of 1.4 and 1.7. Using Eq. 4 and a live loadto-dead load ratio of $1.0, \phi_{d}$ equals 0.93 for bars without transverse reinforcement and $0.92\left(R_{r}=\right.$ $0.0727)$ and $0.91\left(R_{\mathrm{r}}=0.1275\right)$ for bars with transverse reinforcement. Using Eq. 5, the respective values are $0.89,0.99$, and 0.97 .

$\phi_{d}=0.9$ appears to be generally conservative and satisfactory for application with Eqs. 4 and 5 for both sets of load factors. The lower values of $\phi_{d}$ for bars without confining reinforcement obtained for Eq. 5 compared to Eq. 4 pose no safety problems, since $l_{d}$ obtained with Eq. 5 is never shorter than $l_{d}$ obtained with Eq. 4 . The lower values of $\phi_{d}$ calculated for Eq. 5 are due to the greater scatter (higher $\mathrm{V}_{\mathrm{r}}$ ) obtained with Eq. 5, as shown in Table 1 .

Table 1 demonstrates that an increase in the live load-to-dead load ratio results in a reduc- 
tion in the $\phi$-factor. This reduction is due to the increased variability, represented by $V_{\phi q}$, that results from the greater uncertainty in the live load.

Design Expressions-For ease in application, $\phi_{d}$ can be incorporated directly into the design expressions so that its value becomes transparent to the user. Multiplying the right side of Eqs. 4 and 5 by $\phi_{d}=0.9$, setting $f_{s}=f_{y}$, and solving for $l_{d} / d_{b}$ gives, respectively,

$$
\begin{aligned}
& \frac{l_{d}}{d_{b}}=\frac{\frac{f_{y}}{f_{c}^{\prime 1 / 4}}-1900\left(0.1 \frac{c_{M}}{c_{m}}+0.9\right)}{72\left(\frac{c+K_{t r}}{d_{b}}\right)} \\
& \frac{l_{d}}{d_{b}}=\frac{\frac{f_{y}}{f_{c}^{\prime 1 / 4}}-1900}{72\left(\frac{c+K_{t r}}{d_{b}}\right)}
\end{aligned}
$$

The development and splice lengths obtained with Eqs. 37 and 38 are compared with those obtained using the provisions of ACI 318-89 and ACI 318-95 for both conventional and high relative rib area bars by Darwin et al. (1995b).

The analysis described here provides an important advantage over current design procedures (ACI 318-89, ACI 318-95, AASHTO Highway 1992) in that Eqs. 37 and 38 apply directly to both development and splice lengths, since the equation calibration and $\phi$-factor calculations are based on data that consists predominantly of splice tests in which all bars are spliced at the same location; over 90 percent of the specimens used to establish Eq. 1 contain Class B (ACI)/Class C (AASHTO) splices (Darwin et al. 1995b). Thus, following the procedures described here and by Darwin et al. (1995b) eliminates the need to multiply $l_{d}$ by 1.3 (ACI) or 1.7 (AASHTO) to obtain the length of most splices. 


\section{SUMMARY AND CONCLUSIONS}

The formulation and calculation of a reliability-based strength-reduction $(\phi)$ factor for developed and spliced bars is described. Conventional and high relative rib area bars, both with and without confining reinforcement, are considered. The $\phi$-factor is determined using statistically-based expressions for development/splice strength and Monte Carlo simulations of a range of beams.

A strength-reduction factor of 0.9 is obtained for the design expressions for development/splice length, based on a probability of failure in bond equal to about one-fifth of the probability of failure in bending or combined bending and compression. $\phi=0.9$ is incorporated into two expressions for development/splice length in a manner that is transparent to the user. A major advantage of each of the final expressions is that they provide identical values for development and splice length, removing the need to multiply development length by 1.3 or 1.7 to obtain the length of most splices.

\section{REFERENCES}

AASHTO Highway Sub-Committee on Bridges and Structures. 1992. Standard Specifications for Highway Bridges, 15th Edition, American Association of State Highway and Transportation Officials, Washington, DC, $686 \mathrm{pp}$.

ACI Committee 117. 1990. Standard Specifications for Tolerances for Concrete Construction (ACI 117-90), American Concrete Institute, Detroit, MI, 12 pp.

ACI Committee 318. 1989. Building Code Requirements for Reinforced Concrete (ACI 318-89) and Commentary - ACI 318R-89, American Concrete Institute, Detroit, MI, 353 pp.

ACI Committee 318. 1994. "Proposed Revisions to Building Code Requirements for Reinforced Concrete (ACI 318-89) (Revised 1992) and Commentary - ACI 318R-89 (Revised 1992),"Concrete International, Vol. 16, No. 12, Dec., pp. 76-128. Cited as ACI 318-95.

ASCE 1993. Minimum Design Loads for Buildings and Other Structures, ASCE 7-93, American Society of Civil Engineers, New York.

ASTM. "Standard Test Method for Compressive Strength of Cylindrical Concrete Specimens (ASTM C 39-93a)," 1994 Annual Book of ASTM Standards, Vol. 04.02, American Society of 
Testing and Materials, Philadelphia, PA, pp. 17-21.

Azizinamini, A; Stark, M.; Roller, John J.; and Ghosh, S. K. 1993. "Bond Performance of Reinforcing Bars Embedded in High-Strength Concrete," ACI Structural Journal, Vol. 95, No. 5, Sept.-Oct., pp. 554-561.

Azizinamini, A; Chisala, M.; and Ghosh, S. K. 1995. "Tension Development Length of Reinforcing Bars Embedded in High-Strength Concrete," Engineering Structures, in press.

Chamberlin, S. J. 1956. "Spacing of Reinforcement in Beams," ACI Journal, Proceedings Vol. 53, No. 1, July, pp. 113-134.

Chamberlin, S. J. 1958. "Spacing of Spliced Bars in Beams," ACI Journal, Proceedings Vol. 54, No. 8 , Feb., pp. 689-698.

Chinn, James; Ferguson, Phil M.; and Thompson, J. Neils 1955. "Lapped Splices in Reinforced Concrete Beams," ACI Journal, Proceedings Vol. 52, No. 2, Oct., pp. 201-214.

Choi, Oan Chul; Hadje-Ghaffari, Hossain; Darwin, David, and McCabe Steven L. 1990. "Bond of Epoxy-Coated Reinforcement to Concrete: Bar Parameters," SL Report No. 90-1, University of Kansas Center for Research, Lawrence, Kansas, Jan., 43 pp.

Choi, Oan Chul; Hadje-Ghaffari, Hossain; Darwin, David, and McCabe Steven L. 1991. "Bond of Epoxy-Coated Reinforcement: Bar Parameters," ACI Materials Journal, Vol. 88, No. 2, MarchApril, pp. 207-217.

Darwin, D. and Graham, E. K. 1993a. "Effect of Deformation Height and Spacing on Bond Strength of Reinforcing Bars," SL Report 93-1, University of Kansas Center for Research, Lawrence, Kansas, January, 68 pp.

Darwin, D. and Graham, E. K. 1993b. "Effect of Deformation Height and Spacing on Bond Strength of Reinforcing Bars," ACI Structural Journal, Nov.-Dec., Vol. 90, No. 6, pp. 646-657.

Darwin, D.; Tholen, Michael L.; Idun, Emmanuel K.; and Zuo, Jun. 1995a. "Splice Strength of High Relative Rib Area Reinforcing Bars," SL Report 95-3, University of Kansas Center for Research, Lawrence, Kansas, May, 58 pp.

Darwin, D.; Zuo, Jun; Tholen, Michael L.; and Idun, Emmanuel K. 1995b. "Development Length Criteria for Conventional and High Relative Rib Area Reinforcing Bars," SL Report 95-4, University of Kansas Center for Research, Lawrence, Kansas, May, 70 pp.

DeVries, R. A.; Moehle, J. P.; and Hester, W. 1991. "Lap Splice Strength of Plain and EpoxyCoated Reinforcement," Report No. UCB/SEMM-91/02, University of California, Berkeley, California, Jan., 86 pp.

Ellingwood, Bruce; Galambos, Theodore V.; MacGregor, James G.; and Cornell, C. Allin. 1980. "Development of a Probability Based Criterion for American National Standard A58," NBS Special Publication 577, U.S. Dept. of Commerce, Washington, D.C., June, 222 pp.

Ferguson, Phil M. and Thompson, J. Neils. 1965. "Development Length of High Strength Reinforcing Bars," ACI Journal, Proceedings, Vol. 62, No. 1, Jan., pp. 71-94.

Ferguson, Phil M. and Breen, John E. 1965. "Lapped Splices for High Strength Reinforcing 
Bars," ACI Journal, Proceedings, Vol. 62, No. 9, Sept., pp. 1063-1078.

Grant, Leon H.; Mirza, S. Ali; and MacGregor, James G. 1978. "Monte Carlo Study of Strength of Concrete Columns," ACI Journal, Proceedings Vol. 75, No. 8, Aug., pp 348-358.

Hester, Cynthia J.; Salamizavaregh, Shahin; Darwin, David; and McCabe, Steven L. 1991. "Bond of Epoxy-Coated Reinforcement to Concrete: Splices," SL Report 91-1, University of Kansas Center for Research, Lawrence, Kansas, May, 66 pp.

Hester, Cynthia J.; Salamizavaregh, Shahin; Darwin, David; and McCabe, Steven L. 1993. "Bond of Epoxy-Coated Reinforcement: Splices," ACI Structural Journal, Vol. 90, No. 1, Jan.-Feb., pp. 89-102.

Jones, P. G. and Richart, F. E. 1936. "The Effect of Testing Speed on Strength and Elastic Properties of Concrete," Proceedings, ASTM, Vol. 36, Part II, pp. 380-391.

Lundberg, Jane E. 1993. "The Reliability of Composite Columns and Beam Columns," Structural Engineering Report No. 93-2, University of Minnesota, Minneapolis, Minnesota, June, 233 pp.

Mathey, Robert and Watstein, David 1961. "Investigation of Bond in Beam and Pull-Out Specimens with High-Yield-Strength Deformed Bars," ACI Journal, Proceedings Vol. 32, No. 9, Mar., pp. 1071-1090.

Mirza, S. Ali; Hatzinikolas, Michael; and MacGregor, James G. 1979. "Statistical Descriptions of Strength of Concrete," Journal of the Structural Division, ASCE, Vol. 105, No. ST6, June, pp. 1027-1037.

Mirza, S. Ali and MacGregor, James G. 1986. "Strength Variability of Bond of Reinforcing Bars in Concrete Beams," Civil Engineering Report Series No. CE-86-1, Lakehead University, Thunder Bay, Ontario, Jan., 35 pp.

Rezansoff, T.; Konkankar, U. S.; and Fu, Y. C. 1991. "Confinement Limits for Tension Lap Splices under Static Loading", Report, University of Saskatchewan, Saskatoon, Sask., Aug., 24 pp.

Rezansoff, T.; Akanni, A; and Sparling, B. 1993. "Tensile Lap Splices under Static Loading: A Review of The Proposed ACI 318 Code Provisions," ACI Structural Journal, Vol. 90, No. 4, July-Aug., pp. 374-384.

Thompson, M. A.; Jirsa, J. O.; Breen, J. E,; and Meinheit, D. F. 1975. "The Behavior of Multiple Lap Splices in Wide Sections," Research Report No. 154-1, Center for Highway Research, The University of Texas at Austin, Feb., 75 pp.

Zekany, A. J.; Neumann, S.; and Jirsa, J. O. 1981. "The Influence of Shear on Lapped Splices in Reinforced Concrete," Research Report No. 242-2, Center for Transportation Research, Bureau of Engineering Research, University of Texas at Austin, July, 88 pp. 
Table 1

\section{Strength Reduction $(\phi)$ Factors for Bond}

Eq. 4

$$
\gamma_{D}=1.4 \quad \gamma_{L}=1.7 \quad\left(\phi_{\text {bending }}=0.9\right)
$$

\begin{tabular}{|c|c|c|c|c|c|c|c|c|c|}
\hline & \multicolumn{3}{|c|}{ Without Stirrups } & \multicolumn{6}{|c|}{ With Stirrups } \\
\hline$\underset{\bar{r}}{\text { Average }} R_{r}$ & & N/A & & & $\begin{array}{c}0.0727 \\
0.989\end{array}$ & & & $\begin{array}{l}0.1275 \\
0.880\end{array}$ & \\
\hline $\mathrm{V}_{\mathrm{s}}$ & & 0.106 & & & 0.125 & & & 0.125 & \\
\hline$\left(Q_{p} / Q_{p}\right)_{0}$ & 0.5 & 1.0 & 1.5 & 0.5 & 1.0 & 1.5 & 0.5 & 1.0 & 1.5 \\
\hline$\overline{\mathrm{q}}$ & 0.675 & 0.647 & 0.631 & 0.675 & 0.647 & 0.631 & 0.675 & 0.647 & 0.631 \\
\hline$V_{\infty}$ & 0.102 & 0.131 & 0.152 & 0.102 & 0.131 & 0.152 & 0.102 & 0.131 & 0.152 \\
\hline$\phi_{\mathrm{b}}$ & 0.846 & 0.819 & 0.792 & 0.833 & 0.812 & 0.788 & 0.826 & 0.805 & 0.780 \\
\hline$\phi_{d}$ & 0.940 & 0.910 & 0.880 & 0.926 & 0.902 & 0.875 & 0.917 & 0.894 & 0.867 \\
\hline
\end{tabular}

\begin{tabular}{|c|c|c|c|c|c|c|c|c|c|}
\hline & \multicolumn{3}{|c|}{ Without Stirrups } & \multicolumn{6}{|c|}{ With Stirrups } \\
\hline Average $R_{r}$ & & N/A & & & 0.0727 & & & 0.1275 & \\
\hline$\overline{\mathrm{r}}$ & & 0.955 & & & 0.989 & & & 0.980 & \\
\hline$V_{r}$ & & 0.106 & & & 0.125 & & & 0.125 & \\
\hline$\left(Q_{D} / Q_{L}\right)_{n}$ & 0.5 & 1.0 & 1.5 & 0.5 & 1.0 & 1.5 & 0.5 & 1.0 & 1.5 \\
\hline$\overline{\mathrm{q}}$ & 0.759 & 0.716 & 0.693 & 0.759 & 0.716 & 0.693 & 0.759 & 0.716 & 0.693 \\
\hline$V_{\phi q}$ & 0.102 & 0.131 & 0.152 & 0.102 & 0.131 & 0.152 & 0.102 & 0.131 & 0.152 \\
\hline$\phi_{\mathrm{b}}$ & 0.752 & 0.740 & 0.722 & 0.741 & 0.733 & 0.718 & 0.734 & 0.727 & 0.711 \\
\hline$\phi_{d}$ & 0.940 & 0.925 & 0.902 & 0.926 & 0.917 & 0.897 & 0.917 & 0.908 & 0.889 \\
\hline
\end{tabular}

$$
\gamma_{D}=1.2 \quad \gamma_{L}=1.6 \quad\left(\phi_{\text {bendine }}=0.8\right)
$$


Table 1

Strength Reduction ( $\phi$ ) Factors for Bond (continued)

Eq. 5

$\gamma_{D}=1.4 \quad \gamma_{L}=1.7 \quad\left(\phi_{\text {bending }}=0.9\right)$

\begin{tabular}{|c|c|c|c|c|c|c|c|c|c|}
\hline & \multicolumn{3}{|c|}{ Without Stirrups } & \multicolumn{6}{|c|}{ With Stirrups } \\
\hline Average $R_{r}$ & \multirow{2}{*}{\multicolumn{3}{|c|}{$\begin{array}{c}\mathrm{N} / \mathrm{A} \\
1.046\end{array}$}} & \multicolumn{3}{|c|}{0.0727} & \multicolumn{3}{|c|}{0.1275} \\
\hline$\overline{\mathrm{r}}$ & & & & & 1.136 & & & 1.101 & \\
\hline$V_{t}$ & & 0.159 & & & 0.150 & & & 0.146 & \\
\hline$\left(Q_{D} / Q_{L}\right)_{n}$ & 0.5 & 1.0 & 1.5 & 0.5 & 1.0 & 1.5 & 0.5 & 1.0 & 1.5 \\
\hline $\bar{q}$ & 0.675 & 0.647 & 0.631 & 0.675 & 0.647 & 0.631 & 0.675 & 0.647 & 0.631 \\
\hline$V_{\phi q}$ & 0.102 & 0.131 & 0.152 & 0.102 & 0.131 & 0.152 & 0.102 & 0.131 & 0.152 \\
\hline$\phi_{\mathrm{b}}$ & 0.800 & 0.787 & 0.768 & 0.892 & 0.875 & 0.853 & 0.875 & 0.857 & 0.835 \\
\hline$\phi_{d}$ & 0.889 & 0.874 & 0.853 & 0.991 & 0.973 & 0.948 & 0.972 & 0.953 & 0.928 \\
\hline
\end{tabular}

$$
\gamma_{D}=1.2 \quad \gamma_{L}=1.6 \quad\left(\phi_{\text {bending }}=0.8\right)
$$

\begin{tabular}{|c|c|c|c|c|c|c|c|c|c|}
\hline & \multicolumn{3}{|c|}{ Without Stirrups } & \multicolumn{6}{|c|}{ With Stirrups } \\
\hline Average $R_{r}$ & & N/A & & & 0.0727 & & & 0.1275 & \\
\hline$\overline{\mathbf{r}}$ & & 1.046 & & & 1.136 & & & 1.101 & \\
\hline $\mathrm{V}_{\mathrm{r}}$ & & 0.159 & & & 0.150 & & & 0.146 & \\
\hline$\left(Q_{D} / Q_{L}\right)_{n}$ & 0.5 & 1.0 & 1.5 & 0.5 & 1.0 & 1.5 & 0.5 & 1.0 & 1.5 \\
\hline$\overline{\mathrm{q}}$ & 0.759 & 0.716 & 0.693 & 0.759 & 0.716 & 0.693 & 0.759 & 0.716 & 0.693 \\
\hline$V_{\phi \phi_{1}}$ & 0.102 & 0.131 & 0.152 & 0.102 & 0.131 & 0.152 & 0.102 & 0.131 & 0.152 \\
\hline$\phi_{\mathrm{b}}$ & 0.711 & 0.711 & 0.700 & 0.793 & 0.791 & 0.778 & 0.778 & 0.774 & 0.761 \\
\hline$\phi_{\mathrm{d}}$ & 0.889 & 0.888 & 0.875 & 0.991 & 0.988 & 0.972 & 0.972 & 0.968 & 0.951 \\
\hline
\end{tabular}




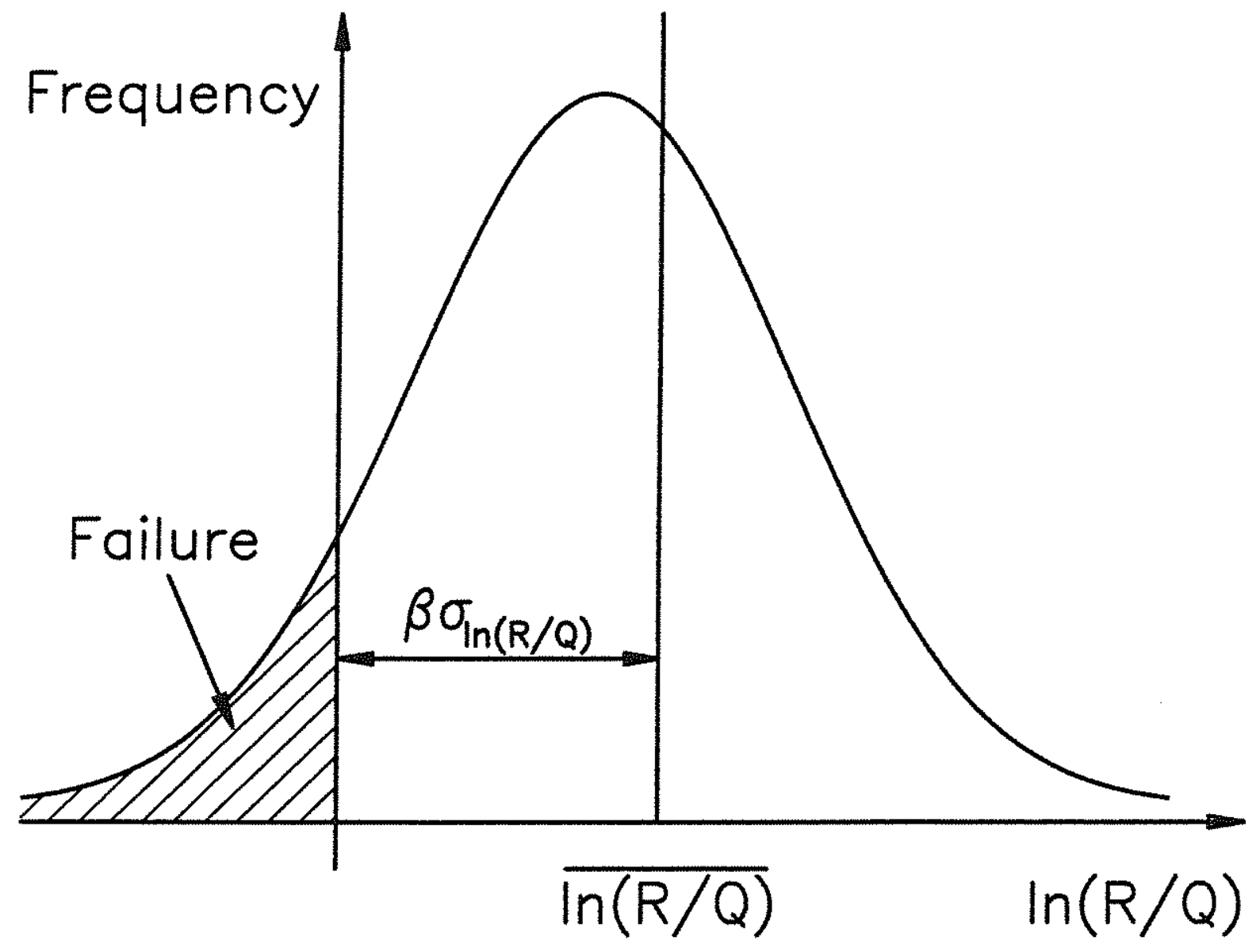

Fig. 1 Mlustration of reliability index (after Ellingwood et al. 1980). $\beta$ = number of standard deviations, $\sigma_{\ln (R / Q)}$, between $\ln (R / Q)=\overline{\ln (R / Q)}$ and $\ln (R / Q)=0$. 


\section{Appendix A}

Table A.1

Data for hypothetical beams used for the Monte Carlo Analyses

(a)

(without confining reinforcement)

\begin{tabular}{|c|c|c|c|c|c|c|c|c|c|}
\hline Beam No. & $\mathrm{n}$ & $\begin{array}{c}l_{d}{ }^{*} \\
\text { (in.) }\end{array}$ & $\begin{array}{c}\mathrm{d}_{\mathrm{b}} \\
\text { (in.) }\end{array}$ & $\begin{array}{c}\mathrm{b} \\
\text { (in.) }\end{array}$ & $\begin{array}{c}\mathrm{h} \\
\text { (in.) }\end{array}$ & $\begin{array}{c}\mathrm{c}_{\text {so }} \\
\text { (in.) }\end{array}$ & $\begin{array}{c}\mathrm{c}_{\mathrm{si}} \\
\text { (in.) }\end{array}$ & $\begin{array}{c}\mathrm{c}_{\mathrm{b}} \\
\text { (in.) }\end{array}$ & $\begin{array}{c}\mathrm{f}_{\mathrm{c}} \\
\text { (psi) }\end{array}$ \\
\hline 1 & 2 & 31.38 & 0.75 & 8.00 & 12.00 & 2.00 & 0.50 & 2.00 & 4000 \\
\hline 2 & 2 & 18.39 & 0.75 & 12.00 & 12.00 & 2.00 & 2.50 & 2.00 & 4000 \\
\hline 3 & 2 & 31.36 & 1.00 & 12.00 & 12.00 & 2.00 & 2.00 & 2.00 & 4000 \\
\hline 4 & 2 & 52.55 & 1.27 & 12.00 & 12.00 & 2.00 & 1.46 & 2.00 & 4000 \\
\hline 5 & 2 & 68.79 & 1.41 & 12.00 & 12.00 & 2.00 & 1.18 & 2.00 & 4000 \\
\hline 6 & 2 & 18.39 & 0.75 & 24.00 & 12.00 & 2.00 & 8.50 & 2.00 & 4000 \\
\hline 7 & 4 & 18.39 & 0.75 & 24.00 & 12.00 & 2.00 & 2.33 & 2.00 & 4000 \\
\hline 8 & 6 & 23.76 & 0.75 & 24.00 & 12.00 & 2.00 & 1.10 & 2.00 & 4000 \\
\hline 9 & 8 & 30.36 & 0.75 & 24.00 & 12.00 & 2.00 & 0.57 & 2.00 & 4000 \\
\hline 10 & 2 & 31.36 & 1.00 & 24.00 & 12.00 & 2.00 & 8.00 & 2.00 & 4000 \\
\hline 11 & 4 & 31.36 & 1.00 & 24.00 & 12.00 & 2.00 & 2.00 & 2.00 & 4000 \\
\hline 12 & 6 & 44.96 & 1.00 & 24.00 & 12.00 & 2.00 & 0.80 & 2.00 & 4000 \\
\hline 13 & 2 & 47.84 & 1.27 & 24.00 & 12.00 & 2.00 & 7.46 & 2.00 & 4000 \\
\hline 14 & 4 & 49.53 & 1.27 & 24.00 & 12.00 & 2.00 & 1.64 & 2.00 & 4000 \\
\hline 15 & 2 & 57.24 & 1.41 & 24.00 & 12.00 & 2.00 & 7.18 & 2.00 & 4000 \\
\hline 16 & 4 & 62.82 & 1.41 & 24.00 & 12.00 & 2.00 & 1.45 & 2.00 & 4000 \\
\hline 17 & 2 & 20.23 & 0.75 & 12.00 & 24.00 & 2.00 & 2.50 & 2.00 & 3000 \\
\hline 18 & 2 & 18.39 & 0.75 & 12.00 & 24.00 & 2.00 & 2.50 & 2.00 & 4000 \\
\hline 19 & 2 & 16.01 & 0.75 & 12.00 & 24.00 & 2.00 & 2.50 & 2.00 & 6000 \\
\hline 20 & 2 & 34.50 & 1.00 & 12.00 & 24.00 & 2.00 & 2.00 & 2.00 & 3000 \\
\hline 21 & 2 & 31.36 & 1.00 & 12.00 & 24.00 & 2.00 & 2.00 & 2.00 & 4000 \\
\hline 22 & 2 & 27.31 & 1.00 & 12.00 & 24.00 & 2.00 & 2.00 & 2.00 & 6000 \\
\hline 23 & 2 & 57.84 & 1.27 & 12.00 & 24.00 & 2.00 & 1.46 & 2.00 & 3000 \\
\hline 24 & 2 & 52.55 & 1.27 & 12.00 & 24.00 & 2.00 & 1.46 & 2.00 & 4000 \\
\hline 25 & 2 & 45.72 & 1.27 & 12.00 & 24.00 & 2.00 & 1.46 & 2.00 & 6000 \\
\hline 26 & 2 & 75.77 & 1.41 & 12.00 & 24.00 & 2.00 & 1.18 & 2.00 & 3000 \\
\hline 27 & 2 & 68.79 & 1.41 & 12.00 & 24.00 & 2.00 & 1.18 & 2.00 & 4000 \\
\hline 28 & 2 & 59.78 & 1.41 & 12.00 & 24.00 & 2.00 & 1.18 & 2.00 & 6000 \\
\hline 29 & 4 & 21.53 & 0.75 & 18.00 & 24.00 & 2.00 & 1.33 & 2.00 & 4000 \\
\hline 30 & 6 & 31.38 & 0.75 & 18.00 & 24.00 & 2.00 & 0.50 & 2.00 & 4000 \\
\hline 31 & 2 & 31.36 & 1.00 & 18.00 & 24.00 & 2.00 & 5.00 & 2.00 & 4000 \\
\hline 32 & 4 & 41.41 & 1.00 & 18.00 & 24.00 & 2.00 & 1.00 & 2.00 & 4000 \\
\hline 33 & 2 & 47.84 & 1.27 & 18.00 & 24.00 & 2.00 & 4.46 & 2.00 & 4000 \\
\hline 34 & 4 & 70.37 & 1.27 & 18.00 & 24.00 & 2.00 & 0.64 & 2.00 & 4000 \\
\hline 35 & 2 & 57.24 & 1.41 & 18.00 & 24.00 & 2.00 & 4.18 & 2.00 & 4000 \\
\hline
\end{tabular}


Table A.1

Data for hypothetical beams used for the Monte Carlo Analyses (continued)

(b)

(with confining reinforcement)

\begin{tabular}{|c|c|c|c|c|c|c|c|c|c|c|c|c|}
\hline \multirow[t]{2}{*}{ Beam No. } & \multirow[t]{2}{*}{$\mathrm{n}$} & \multicolumn{2}{|c|}{$l_{d}^{*}$} & \multirow[t]{2}{*}{$d_{b}$} & \multirow[t]{2}{*}{$\mathrm{b}$} & \multirow[t]{2}{*}{$\mathrm{h}$} & \multirow[t]{2}{*}{$c_{\text {so }}$} & \multirow[t]{2}{*}{$\mathrm{c}_{\mathrm{si}}$} & $c_{b}$ & $f_{c}$ & $A_{t r}$ & \\
\hline & & $\begin{aligned} \mathrm{R}_{\mathrm{r}}= & 0.0727 \\
& \text { (in.) }\end{aligned}$ & $\begin{array}{c}\mathrm{R}_{\mathrm{r}}=0.1275 \\
\text { (in.) }\end{array}$ & & & & & & & (psi) & $\left(\right.$ in. $\left.{ }^{2}\right)$ & \\
\hline \multicolumn{13}{|l|}{ Group 1 } \\
\hline 1 & 2 & 21.01 & 17.84 & 0.75 & 8.00 & 12.00 & 2.00 & 0.50 & 2.00 & 4000 & 0.110 & 4.81 \\
\hline 2 & 2 & 14.45 & 12.95 & 0.75 & 12.00 & 12.00 & 2.00 & 2.50 & 2.00 & 4000 & 0.110 & 4.81 \\
\hline 3 & 2 & 23.76 & 21.02 & 1.00 & 12.00 & 12.00 & 2.00 & 2.00 & 2.00 & 4000 & 0.110 & 4.75 \\
\hline 4 & 2 & 37.36 & 32.33 & 1.27 & 12.00 & 12.00 & 2.00 & 1.46 & 2.00 & 4000 & 0.110 & 4.68 \\
\hline 5 & 2 & 46.57 & 39.68 & 1.41 & 12.00 & 12.00 & 2.00 & 1.18 & 2.00 & 4000 & 0.110 & 4.65 \\
\hline 6 & 2 & 14.45 & 12.95 & 0.75 & 24.00 & 12.00 & 2.00 & 8.50 & 2.00 & 4000 & 0.110 & 4.81 \\
\hline 7 & 4 & 16.18 & 15.20 & 0.75 & 24.00 & 12.00 & 2.00 & 2.33 & 2.00 & 4000 & 0.055 & 4.81 \\
\hline 8 & 6 & 21.22 & 20.07 & 0.75 & 24.00 & 12.00 & 2.00 & 1.10 & 2.00 & 4000 & 0.037 & 4.81 \\
\hline 9 & 8 & 27.15 & 25.69 & 0.75 & 24.00 & 12.00 & 2.00 & 0.57 & 2.00 & 4000 & 0.028 & 4.81 \\
\hline 10 & 2 & 23.76 & 21.02 & 1.00 & 24.00 & 12.00 & 2.00 & 8.00 & 2.00 & 4000 & 0.110 & 4.75 \\
\hline 11 & 4 & 27.04 & 25.17 & 1.00 & 24.00 & 12.00 & 2.00 & 2.00 & 2.00 & 4000 & 0.055 & 4.75 \\
\hline 12 & 6 & 38.83 & 36.18 & 1.00 & 24.00 & 12.00 & 2.00 & 0.80 & 2.00 & 4000 & 0.037 & 4.75 \\
\hline 13 & 2 & 34.97 & 30.55 & 1.27 & 24.00 & 12.00 & 2.00 & 7.46 & 2.00 & 4000 & 0.110 & 4.68 \\
\hline 14 & 4 & 41.59 & 38.29 & 1.27 & 24.00 & 12.00 & 2.00 & 1.64 & 2.00 & 4000 & 0.055 & 4.68 \\
\hline 15 & 2 & 41.13 & 35.72 & 1.41 & 24.00 & 12.00 & 2.00 & 7.18 & 2.00 & 4000 & 0.110 & 4.65 \\
\hline 16 & 4 & 51.65 & 47.14 & 1.41 & 24.00 & 12.00 & 2.00 & 1.45 & 2.00 & 4000 & 0.055 & 4.65 \\
\hline 17 & 2 & 18.04 & 17.04 & 0.75 & 12.00 & 24.00 & 2.00 & 2.50 & 2.00 & 3000 & 0.110 & 10.81 \\
\hline 18 & 2 & 16.40 & 15.50 & 0.75 & 12.00 & 24.00 & 2.00 & 2.50 & 2.00 & 4000 & 0.110 & 10.81 \\
\hline 19 & 2 & 14.28 & 13.49 & 0.75 & 12.00 & 24.00 & 2.00 & 2.50 & 2.00 & 6000 & 0.110 & 10.81 \\
\hline 20 & 2 & 30.22 & 28.34 & 1.00 & 12.00 & 24.00 & 2.00 & 2.00 & 2.00 & 3000 & 0.110 & 10.75 \\
\hline 21 & 2 & 27.48 & 25.76 & 1.00 & 12.00 & 24.00 & 2.00 & 2.00 & 2.00 & 4000 & 0.110 & 10.75 \\
\hline 22 & 2 & 23.93 & 22.43 & 1.00 & 12.00 & 24.00 & 2.00 & 2.00 & 2.00 & 6000 & 0.110 & 10.75 \\
\hline 23 & 2 & 49.09 & 45.39 & 1.27 & 12.00 & 24.00 & 2.00 & 1.46 & 2.00 & 3000 & 0.110 & 10.68 \\
\hline 24 & 2 & 44.60 & 41.25 & 1.27 & 12.00 & 24.00 & 2.00 & 1.46 & 2.00 & 4000 & 0.110 & 10.68 \\
\hline 25 & 2 & 38.81 & 35.89 & 1.27 & 12.00 & 24.00 & 2.00 & 1.46 & 2.00 & 6000 & 0.110 & 10.68 \\
\hline 26 & 2 & 62.71 & 57.39 & 1.41 & 12.00 & 24.00 & 2.00 & 1.18 & 2.00 & 3000 & 0.110 & 10.65 \\
\hline 27 & 2 & 56.94 & 52.11 & 1.41 & 12.00 & 24.00 & 2.00 & 1.18 & 2.00 & 4000 & 0.110 & 10.65 \\
\hline 28 & 2 & 49.48 & 45.28 & 1.41 & 12.00 & 24.00 & 2.00 & 1.18 & 2.00 & 6000 & 0.110 & 10.65 \\
\hline 29 & 4 & 19.05 & 17.94 & 0.75 & 18.00 & 24.00 & 2.00 & 1.33 & 2.00 & 4000 & 0.100 & 10.81 \\
\hline 30 & 6 & 27.70 & 26.05 & 0.75 & 18.00 & 24.00 & 2.00 & 0.50 & 2.00 & 4000 & 0.067 & 10.81 \\
\hline 31 & 2 & 24.95 & 22.48 & 1.00 & 18.00 & 24.00 & 2.00 & 5.00 & 2.00 & 4000 & 0.200 & 10.75 \\
\hline 32 & 4 & 35.29 & 32.69 & 1.00 & 18.00 & 24.00 & 2.00 & 1.00 & 2.00 & 4000 & 0.100 & 10.75 \\
\hline 33 & 2 & 36.99 & 32.97 & 1.27 & 18.00 & 24.00 & 2.00 & 4.46 & 2.00 & 4000 & 0.200 & 10.68 \\
\hline 34 & 4 & 57.43 & 52.26 & 1.27 & 18.00 & 24.00 & 2.00 & 0.64 & 2.00 & 4000 & 0.100 & 10.68 \\
\hline 35 & 2 & 43.67 & 38.73 & 1.41 & 18.00 & 24.00 & 2.00 & 4.18 & 2.00 & 4000 & 0.200 & 10.65 \\
\hline
\end{tabular}


Table A.1

Data for hypothetical beams used for the Monte Carlo Analyses (continued)

(b)

(with confining reinforcement)

\begin{tabular}{|c|c|c|c|c|c|c|c|c|c|c|c|c|}
\hline Beam No. & $\mathrm{n}$ & $\begin{array}{c}\mathrm{R}_{\mathrm{r}}=0.0727 \\
\quad \text { (in.) }\end{array}$ & $\begin{array}{l}\mathrm{R}_{\mathrm{r}}=0.1275 \\
\quad \text { (in.) }\end{array}$ & (in.) & (in.) & (in.) & (in.) & (in.) & (in.) & (psi) & $\left(\right.$ in. $\left.{ }^{2}\right)$ & (in.) \\
\hline \multicolumn{13}{|l|}{ Group 2} \\
\hline 1 & 2 & 17.17 & 14.23 & 0.75 & 8.50 & 12.00 & 2.00 & 0.75 & 2.00 & 4000 & 0.200 & 6.00 \\
\hline 2 & 2 & 17.17 & 14.23 & 0.75 & 8.50 & 12.00 & 2.00 & 0.75 & 2.00 & 4000 & 0.200 & 6.00 \\
\hline 3 & 2 & 25.54 & 21.18 & 1.00 & 10.00 & 12.00 & 2.00 & 1.00 & 2.00 & 4000 & 0.200 & 6.00 \\
\hline 4 & 2 & 34.65 & 28.74 & 1.27 & 11.62 & 12.00 & 2.00 & 1.27 & 2.00 & 4000 & 0.200 & 6.00 \\
\hline 5 & 2 & 39.37 & 32.66 & 1.41 & 12.46 & 12.00 & 2.00 & 1.41 & 2.00 & 4000 & 0.200 & 6.00 \\
\hline 6 & 2 & 17.17 & 14.23 & 0.75 & 8.50 & 12.00 & 2.00 & 0.75 & 2.00 & 4000 & 0.200 & 6.00 \\
\hline 7 & 4 & 21.25 & 18.84 & 0.75 & 14.50 & 12.00 & 2.00 & 0.75 & 2.00 & 4000 & 0.100 & 6.00 \\
\hline 8 & 6 & 23.08 & 21.13 & 0.75 & 20.50 & 12.00 & 2.00 & 0.75 & 2.00 & 4000 & 0.067 & 6.00 \\
\hline 9 & 8 & 24.12 & 22.49 & 0.75 & 26.50 & 12.00 & 2.00 & 0.75 & 2.00 & 4000 & 0.050 & 6.00 \\
\hline 10 & 2 & 25.54 & 21.18 & 1.00 & 10.00 & 12.00 & 2.00 & 1.00 & 2.00 & 4000 & 0.200 & 6.00 \\
\hline 11 & 4 & 31.60 & 28.02 & 1.00 & 18.00 & 12.00 & 2.00 & 1.00 & 2.00 & 4000 & 0.100 & 6.00 \\
\hline 12 & 6 & 34.31 & 31.41 & 1.00 & 26.00 & 12.00 & 2.00 & 1.00 & 2.00 & 4000 & 0.067 & 6.00 \\
\hline 13 & 2 & 34.65 & 28.74 & 1.27 & 11.62 & 12.00 & 2.00 & 1.27 & 2.00 & 4000 & 0.200 & 6.00 \\
\hline 14 & 4 & 42.84 & 38.01 & 1.27 & 21.78 & 12.00 & 2.00 & 1.27 & 2.00 & 4000 & 0.100 & 6.00 \\
\hline 15 & 2 & 39.37 & 32.66 & 1.41 & 12.46 & 12.00 & 2.00 & 1.41 & 2.00 & 4000 & 0.200 & 6.00 \\
\hline 16 & 4 & 48.67 & 43.18 & 1.41 & 23.74 & 12.00 & 2.00 & 1.41 & 2.00 & 4000 & 0.100 & 6.00 \\
\hline 17 & 2 & 18.95 & 15.70 & 0.75 & 8.50 & 24.00 & 2.00 & 0.75 & 2.00 & 3000 & 0.200 & 6.00 \\
\hline 18 & 2 & 17.17 & 14.23 & 0.75 & 8.50 & 24.00 & 2.00 & 0.75 & 2.00 & 4000 & 0.200 & 6.00 \\
\hline 19 & 2 & 14.87 & 12.32 & 0.75 & 8.50 & 24.00 & 2.00 & 0.75 & 2.00 & 6000 & 0.200 & 6.00 \\
\hline 20 & 2 & 28.15 & 23.34 & 1.00 & 10.00 & 24.00 & 2.00 & 1.00 & 2.00 & 3000 & 0.200 & 6.00 \\
\hline 21 & 2 & 25.54 & 21.18 & 1.00 & 10.00 & 24.00 & 2.00 & 1.00 & 2.00 & 4000 & 0.200 & 6.00 \\
\hline 22 & 2 & 22.17 & 18.39 & 1.00 & 10.00 & 24.00 & 2.00 & 1.00 & 2.00 & 6000 & 0.200 & 6.00 \\
\hline 23 & 2 & 38.15 & 31.64 & 1.27 & 11.62 & 24.00 & 2.00 & 1.27 & 2.00 & 3000 & 0.200 & 6.00 \\
\hline 24 & 2 & 34.65 & 28.74 & 1.27 & 11.62 & 24.00 & 2.00 & 1.27 & 2.00 & 4000 & 0.200 & 6.00 \\
\hline 25 & 2 & 30.12 & 24.98 & 1.27 & 11.62 & 24.00 & 2.00 & 1.27 & 2.00 & 6000 & 0.200 & 6.00 \\
\hline 26 & 2 & 43.33 & 35.95 & 1.41 & 12.46 & 24.00 & 2.00 & 1.41 & 2.00 & 3000 & 0.200 & 6.00 \\
\hline 27 & 2 & 39.37 & 32.66 & 1.41 & 12.46 & 24.00 & 2.00 & 1.41 & 2.00 & 4000 & 0.200 & 6.00 \\
\hline 28 & 2 & 34.25 & 28.41 & 1.41 & 12.46 & 24.00 & 2.00 & 1.41 & 2.00 & 6000 & 0.200 & 6.00 \\
\hline 29 & 4 & 21.25 & 18.84 & 0.75 & 14.50 & 24.00 & 2.00 & 0.75 & 2.00 & 4000 & 0.100 & 6.00 \\
\hline 30 & 6 & 23.08 & 21.13 & 0.75 & 20.50 & 24.00 & 2.00 & 0.75 & 2.00 & 4000 & 0.067 & 6.00 \\
\hline 31 & 2 & 25.54 & 21.18 & 1.00 & 10.00 & 24.00 & 2.00 & 1.00 & 2.00 & 4000 & 0.200 & 6.00 \\
\hline 32 & 4 & 31.60 & 28.02 & 1.00 & 18.00 & 24.00 & 2.00 & 1.00 & 2.00 & 4000 & 0.100 & 6.00 \\
\hline 33 & 2 & 34.65 & 28.74 & 1.27 & 11.62 & 24.00 & 2.00 & 1.27 & 2.00 & 4000 & 0.200 & 6.00 \\
\hline 34 & 4 & 42.84 & 38.01 & 1.27 & 21.78 & 24.00 & 2.00 & 1.27 & 2.00 & 4000 & 0.100 & 6.00 \\
\hline 35 & 2 & 39.37 & 32.66 & 1.41 & 12.46 & 24.00 & 2.00 & 1.41 & 2.00 & 4000 & 0.200 & 6.00 \\
\hline
\end{tabular}


Table A.1

Data for hypothetical beams used for the Monte Carlo Analyses (continued)

(b)

(with confining reinforcement)

\begin{tabular}{|c|c|c|c|c|c|c|c|c|c|c|c|c|}
\hline \multirow[t]{2}{*}{ Beam No. } & \multirow[t]{2}{*}{$\mathrm{n}$} & \multicolumn{2}{|r|}{$l_{\mathrm{d}}^{*}$} & \multirow[t]{2}{*}{$\mathrm{d}_{\mathrm{b}}$} & \multirow[t]{2}{*}{$b$} & $\mathrm{~h}$ & $\mathrm{c}_{\mathrm{so}}$ & $\mathrm{c}_{\mathrm{si}}$ & $c_{b}$ & $\mathrm{f}_{\mathrm{c}}$ & $A_{\mathrm{tr}}$ & \multirow{2}{*}{$\begin{array}{c}\mathrm{s} \\
\text { (in.) }\end{array}$} \\
\hline & & $\begin{aligned} \mathrm{R}_{\mathrm{r}}= & 0.0727 \\
& \text { (in.) }\end{aligned}$ & $\begin{array}{c}\mathrm{R}_{\mathrm{r}}=0.1275 \\
\text { (in.) }\end{array}$ & & & & & (in.) & (in.) & (psi) & (in.) & \\
\hline \multicolumn{13}{|l|}{ Group 3} \\
\hline 1 & 2 & 20.38 & 17.15 & 0.75 & 8.00 & 12.00 & 2.00 & 0.50 & 2.00 & 4000 & 0.200 & 8.00 \\
\hline 2 & 2 & 20.38 & 17.15 & 0.75 & 8.00 & 12.00 & 2.00 & 0.50 & 2.00 & 4000 & 0.200 & 8.00 \\
\hline 3 & 2 & 31.85 & 26.54 & 1.00 & 9.00 & 12.00 & 2.00 & 0.50 & 2.00 & 4000 & 0.200 & 8.00 \\
\hline 4 & 2 & 43,98 & 36.58 & 1.27 & 10.35 & 12.00 & 2.00 & 0.64 & 2.00 & 4000 & 0.200 & 8.00 \\
\hline 5 & 2 & 50.35 & 41.84 & 1.41 & 11.05 & 12.00 & 2.00 & 0.71 & 2.00 & 4000 & 0.200 & 8.00 \\
\hline 6 & 2 & 20.38 & 17.15 & 0.75 & 8.00 & 12.00 & 2.00 & 0.50 & 2.00 & 4000 & 0.200 & 8.00 \\
\hline 7 & 4 & 24.71 & 22.18 & 0.75 & 13.00 & 12.00 & 2.00 & 0.50 & 2.00 & 4000 & 0.100 & 8.00 \\
\hline 8 & 6 & 26.60 & 24.58 & 0.75 & 18.00 & 12.00 & 2.00 & 0.50 & 2.00 & 4000 & 0.067 & 8.00 \\
\hline 9 & 8 & 27.65 & 25.99 & 0.75 & 23.00 & 12.00 & 2.00 & 0.50 & 2.00 & 4000 & 0.050 & 8.00 \\
\hline 10 & 2 & 31.85 & 26.54 & 1.00 & 9.00 & 12.00 & 2.00 & 0.50 & 2.00 & 4000 & 0.200 & 8.00 \\
\hline 11 & 4 & 39.13 & 34.84 & 1.00 & 15.00 & 12.00 & 2.00 & 0.50 & 2.00 & 4000 & 0.100 & 8.00 \\
\hline 12 & 6 & 42.35 & 38.90 & 1.00 & 21.00 & 12.00 & 2.00 & 0.50 & 2.00 & 4000 & 0.067 & 8.00 \\
\hline 13 & 2 & 43.98 & 36.58 & 1.27 & 10.35 & 12.00 & 2.00 & 0.64 & 2.00 & 4000 & 0.200 & 8.00 \\
\hline 14 & 4 & 54.16 & 48.16 & 1.27 & 17.97 & 12.00 & 2,00 & 0.64 & 2.00 & 4000 & 0.100 & 8.00 \\
\hline 15 & 2 & 50.35 & 41.84 & 1.41 & 11.05 & 12.00 & 2.00 & 0.71 & 2.00 & 4000 & 0.200 & 8.00 \\
\hline 16 & 4 & 62.08 & 55.17 & 1.41 & 19.51 & 12.00 & 2.00 & 0.71 & 2.00 & 4000 & 0.100 & 8.00 \\
\hline 17 & 2 & 22.54 & 18.97 & 0.75 & 8.00 & 24.00 & 2.00 & 0.50 & 2.00 & 3000 & 0.200 & 8.00 \\
\hline 18 & 2 & 20.38 & 17.15 & 0.75 & 8.00 & 24.00 & 2.00 & 0.50 & 2.00 & 4000 & 0.200 & 8.00 \\
\hline 19 & 2 & 17.59 & 14.80 & 0.75 & 8.00 & 24.00 & 2.00 & 0.50 & 2.00 & 6000 & 0.200 & 8.00 \\
\hline 20 & 2 & 35.22 & 29.35 & 1.00 & 9.00 & 24.00 & 2.00 & 0.50 & 2.00 & 3000 & 0.200 & 8.00 \\
\hline 21 & 2 & 31.85 & 26.54 & 1.00 & 9.00 & 24.00 & 2.00 & 0.50 & 2.00 & 4000 & 0.200 & 8.00 \\
\hline 22 & 2 & 27.48 & 22.90 & 1.00 & 9.00 & 24.00 & 2.00 & 0.50 & 2.00 & 6000 & 0.200 & 8.00 \\
\hline 23 & 2 & 48.57 & 40.40 & 1.27 & 10.35 & 24.00 & 2.00 & 0.64 & 2.00 & 3000 & 0.200 & 8.00 \\
\hline 24 & 2 & 43.98 & 36.58 & 1.27 & 10.35 & 24.00 & 2.00 & 0.64 & 2.00 & 4000 & 0.200 & 8.00 \\
\hline 25 & 2 & 38.04 & 31.64 & 1.27 & 10.35 & 24.00 & 2.00 & 0.64 & 2.00 & 6000 & 0.200 & 8.00 \\
\hline 26 & 2 & 55.58 & 46.19 & 1.41 & 11.05 & 24.00 & 2.00 & 0.71 & 2.00 & 3000 & 0.200 & 8.00 \\
\hline 27 & 2 & 50.35 & 41. & 1.41 & 11.05 & 24.00 & 2.00 & 0.71 & 2.00 & 4000 & 0.200 & 8.00 \\
\hline 28 & 2 & 43.59 & 36.23 & 1.41 & 11.05 & 24.00 & 2.00 & 0.71 & 2.00 & 6000 & 0.200 & 8.00 \\
\hline 29 & 4 & 24.71 & 22.18 & 0.75 & 13.00 & 24.00 & 2.00 & 0.50 & 2.00 & 4000 & 0.100 & 8.00 \\
\hline 30 & 6 & 26.60 & 24.58 & 0.75 & 18.00 & 24.00 & 2.00 & 0.50 & 2.00 & 4000 & 0.067 & 8.00 \\
\hline 31 & 2 & 31.85 & 26.54 & 1.00 & 9.00 & 24.00 & 2,00 & 0.50 & 2.00 & 4000 & 0.200 & 8.00 \\
\hline 32 & 4 & 39.13 & 34.84 & 1.00 & 15.00 & 24.00 & 2.00 & 0.50 & 2.00 & 4000 & 0.100 & 8.00 \\
\hline 33 & 2 & 43.98 & 36.58 & 1.27 & 10.35 & 24,00 & 2.00 & 0.64 & 2.00 & 4000 & 0.200 & 8.00 \\
\hline 34 & 4 & 54.16 & 48.16 & 1.27 & 17.97 & 24.00 & 2.00 & 0.64 & 2.00 & 4000 & 0.100 & 8.00 \\
\hline 35 & 2 & 50.35 & 41.84 & 1.41 & 11.05 & 24.00 & 2.00 & 0.71 & 2.00 & 4000 & 0.200 & 8.00 \\
\hline
\end{tabular}


Table A.1

Data for hypothetical beams used for the Monte Carlo Analyses (continued)

(b)

(with confining reinforcement)

\begin{tabular}{|c|c|c|c|c|c|c|c|c|c|c|c|c|}
\hline \multirow[t]{2}{*}{ Beam No. } & \multirow[t]{2}{*}{$\mathrm{n}$} & \multicolumn{2}{|c|}{$1_{d}^{*}$} & \multirow[t]{2}{*}{$d_{b}$} & $\mathrm{~b}$ & $\mathrm{~h}$ & $c_{50}$ & $\mathrm{c}_{\mathrm{si}}$ & $c_{b}$ & $\mathrm{f}_{\mathrm{c}}$ & $A_{t r}$ & $\mathrm{~s}$ \\
\hline & & $\begin{array}{r}\mathrm{R}_{\mathrm{r}}=0.0727 \\
\text { (in.) }\end{array}$ & $\begin{array}{c}\mathrm{R}_{\mathrm{r}}=0.1275 \\
\text { (in.) }\end{array}$ & & (in.) & (in.) & & (in.) & & (psi) & $\left(\right.$ in. $\left.^{2}\right)$ & \\
\hline \multicolumn{13}{|l|}{ Group 4} \\
\hline 1 & 2 & 15.09 & 11.80 & 0.75 & 8.00 & 12.00 & 2.00 & 0.50 & 2.00 & 4000 & 0.200 & 4.00 \\
\hline 2 & 2 & 15.09 & 11.80 & 0.75 & 8.00 & 12.00 & 2.00 & 0.50 & 2.00 & 4000 & 0.200 & 4.00 \\
\hline 3 & 2 & 23.21 & 17.97 & 1.00 & 9.00 & 12.00 & 2.00 & 0.50 & 2.00 & 4000 & 0.200 & 4.00 \\
\hline 4 & 2 & 31.96 & 24.70 & 1.27 & 10.35 & 12.00 & 2.00 & 0.64 & 2.00 & 4000 & 0.200 & 4.00 \\
\hline 5 & 2 & 36.54 & 28.22 & 1.41 & 11.05 & 12.00 & 2.00 & 0.71 & 2.00 & 4000 & 0.200 & 4.00 \\
\hline 6 & 2 & 15.09 & 11.80 & 0.75 & 8.00 & 12.00 & 2.00 & 0.50 & 2.00 & 4000 & 0.200 & 4.00 \\
\hline 7 & 4 & 20.38 & 17.15 & 0.75 & 13.00 & 12.00 & 2.00 & 0.50 & 2.00 & 4000 & 0.100 & 4.00 \\
\hline 8 & 6 & 23.08 & 20.20 & 0.75 & 18.00 & 12.00 & 2.00 & 0.50 & 2.00 & 4000 & 0.067 & 4.00 \\
\hline 9 & 8 & 24.71 & 22.18 & 0.75 & 23.00 & 12.00 & 2.00 & 0.50 & 2.00 & 4000 & 0.050 & 4.00 \\
\hline 10 & 2 & 23.21 & 17.97 & 1.00 & 9.00 & 12.00 & 2.00 & 0.50 & 2.00 & 4000 & 0.200 & 4.00 \\
\hline 11 & 4 & 31.85 & 26.54 & 1.00 & 15.00 & 12.00 & 2.00 & 0.50 & 2.00 & 4000 & 0.100 & 4.00 \\
\hline 12 & 6 & 36.36 & 1.55 & 1.00 & 21.00 & 12.00 & 2.00 & 0.50 & 2.00 & 4000 & 0.067 & 4.00 \\
\hline 13 & 2 & 31.96 & 24.70 & 1.27 & 10.35 & 12.00 & 2.00 & 0.64 & 2.00 & 4000 & 0.200 & 4.00 \\
\hline 14 & 4 & 43.98 & 36.58 & 1.27 & 17.97 & 12.00 & 2.00 & 0.64 & 2.00 & 4000 & 0.100 & 4.00 \\
\hline 15 & 2 & 36.54 & 28.22 & 1.41 & 11.05 & 12.00 & 2.00 & 0.71 & 2.00 & 4000 & 0.200 & 4.00 \\
\hline 16 & 4 & 50.35 & 41.84 & 1.41 & 19.51 & 12.00 & 2.00 & 0.71 & 2.00 & 4000 & 0.100 & 4.00 \\
\hline 17 & 2 & 16.69 & 13.05 & 0.75 & 8.00 & 24.00 & 2.00 & 0.50 & 2.00 & 3000 & 0.200 & 4.00 \\
\hline 18 & 2 & 15.09 & 11.80 & 0.75 & 8.00 & 24.00 & 2.00 & 0.50 & 2.00 & 4000 & 0.200 & 4.00 \\
\hline 19 & 2 & 13.03 & 10.18 & 0.75 & 8.00 & 24.00 & 2.00 & 0.50 & 2.00 & 6000 & 0.200 & 4.00 \\
\hline 20 & 2 & 25.67 & 19.88 & 1.00 & 9.00 & 24.00 & 2.00 & 0.50 & 2.00 & 3000 & 0.200 & 4.00 \\
\hline 21 & 2 & 23.21 & 17.97 & 1.00 & 9.00 & 24.00 & 2.00 & 0.50 & 2.00 & 4000 & 0.200 & 4.00 \\
\hline 22 & 2 & 20.03 & 15.51 & 1.00 & 9.00 & 24.00 & 2.00 & 0.50 & 2.00 & 6000 & 0.200 & 4.00 \\
\hline 23 & 2 & 35.30 & 27.28 & 1.27 & 10.35 & 24.00 & 2.00 & 0.64 & 2.00 & 3000 & 0.200 & 4.00 \\
\hline 24 & 2 & 31.96 & 24.70 & 1.27 & 10.35 & 24.00 & 2.00 & 0.64 & 2.00 & 4000 & 0.200 & 4.00 \\
\hline 25 & 2 & 27.64 & 21.36 & 1.27 & 10.35 & 24.00 & 2.00 & 0.64 & 2.00 & 6000 & 0.200 & 4.00 \\
\hline 26 & 2 & 40.34 & 31.14 & 1.41 & 11.05 & 24.00 & 2.00 & 0.71 & 2.00 & 3000 & 0.200 & 4.00 \\
\hline 27 & 2 & 36.54 & 28.22 & 1.41 & 11.05 & 24.00 & 2.00 & 0.71 & 2.00 & 4000 & 0.200 & 4.00 \\
\hline 28 & 2 & 31.64 & 24.43 & 1.41 & 11.05 & 24.00 & 2.00 & 0.71 & 2.00 & 6000 & 0.200 & 4.00 \\
\hline 29 & 4 & 20.38 & 17.15 & 0.75 & 13.00 & 24.00 & 2.00 & 0.50 & 2.00 & 4000 & 0.100 & 4.00 \\
\hline 30 & 6 & 23.08 & 20.20 & 0.75 & 18.00 & 24.00 & 2.00 & 0.50 & 2.00 & 4000 & 0.067 & 4.00 \\
\hline 31 & 2 & 23.21 & 17.97 & 1.00 & 9.00 & 24.00 & 2.00 & 0.50 & 2.00 & 4000 & 0.200 & 4.00 \\
\hline 32 & 4 & 31.85 & 26.54 & 1.00 & 15.00 & 24.00 & 2.00 & 0.50 & 2.00 & 4000 & 0.100 & 4.00 \\
\hline 33 & 2 & 31.96 & 24.70 & 1.27 & 10.35 & 24.00 & 2.00 & 0.64 & 2.00 & 4000 & 0.200 & 4.00 \\
\hline 34 & 4 & 43.98 & 36.58 & 1.27 & 17.97 & 24.00 & 2.00 & 0.64 & 2.00 & 4000 & 0.100 & 4.00 \\
\hline 35 & 2 & 36.54 & 28.22 & 1.41 & 11.05 & 24.00 & 2.00 & 0.71 & 2.00 & 4000 & 0.200 & 4.00 \\
\hline
\end{tabular}

Predicted development/splice lengths based on Eq. 2 , using $\phi_{d}=0.9$ and $\mathrm{f}_{\mathrm{y}}=60 \mathrm{ksi}$ 1 in. $=25.4 \mathrm{~mm} ; 1 \mathrm{psi}=6.89 \mathrm{kPa} ; 1 \mathrm{ksi}=6.89 \mathrm{MPa}$ 


\section{Appendix B}

\section{Programs Used For Monte Carlo Simulations}

(a)

Program Bms;

\{MONTE CARLO SIMULATION FOR BEAMS WITHOUT STIRRUPS\}

Uses Crt, Dos;

[DECLARATION OF GLOBAL CONSTANTS FOR THE PROGRAM)

Const

left $=0.0 ;$ tol $=1.0 \mathrm{e}-6$;

\{DECLARATION OF GLOBAL VARIABLES FOR THE PROGRAM)

Var

a, b, z, pz, Ls, Cb, Csi, fc, Db, Ab, Cmin, Cmax, fcm, Cbm, Cim, Lsm, E1m, E2m, R1, R2, h, tc1, tc2, Rc1, Rc2, a0, a1, a2, a3, a4, sd1, s1, $\mathrm{sd} 2, \mathrm{r} 21, \mathrm{r} 22, \mathrm{Vc}, \mathrm{mr} 1, \mathrm{mr} 2, \mathrm{~ms} 1, \mathrm{~ms} 2, \mathrm{mv} 1, \mathrm{mv} 2, \mathrm{~s} 2, \mathrm{~s} 3$, result, errest, Cso, W, Cs, s4, e1, e2, CMm, fcR, Cmind : Real;

$\mathrm{Nb}, \mathrm{Ns}$, err : Byte;

n, 1 : Integer;

$\mathrm{kl}, \mathrm{i}, \mathrm{j}, \mathrm{k}, \mathrm{m}, \mathrm{m0}, \mathrm{hr}, \mathrm{mn}, \mathrm{sec}, \mathrm{sec} 100, \mathrm{hrl}, \mathrm{mn} 1, \sec 1, \sec 1001:$ Word;

fname : String[20];

st : String;

fin, fout, fl : Text;

\{FUNCTION EVALUATES THE EXPRESSION $\mathrm{e}^{\wedge}-\left(0.5^{*} \mathrm{z}^{\wedge} 2\right)$ \}

Function F(z : Real) : Real;

Begin

$\mathrm{F}:=\exp \left(-\mathrm{z}^{*} \mathrm{z} / 2.0\right)$

End;

[FUNCTION EVALUATES THE EXPRESSION FOR SIMPSON'S RULE]

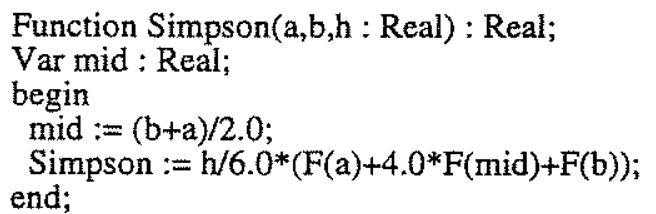

\{NUMERICAL METHOD TO DETERMINE THE CURRENT IMPROVED STANDARD) (NORMAL VALUE, $z[i+1]$, FROM A PREVIOUS VALUE OF $z$ [i] DURING EACH CYCLE] \{OF THE ITERATTVE PROCESS\}

Procedure Adap_Quad(left,z,tol:Real; var result:Real; var errest:Real);

Var h, I1, 12, mid, result1, result2, errest 1, errest 2 : Real;

Begin

$\mathrm{m}:=\mathrm{m}+1$

if $\mathrm{mo}>100$ then

begin

window $(20,23,50,24)$;

writeln(pz:6:4,m0:9,m:9);

end;

$\mathrm{h}:=\mathrm{z}$-left;

I1 := Simpson(left, $\mathrm{z}, \mathrm{h})$;

$h:=h / 2.0$;

mid $:=($ left $+\mathrm{z}) / 2.0$; 


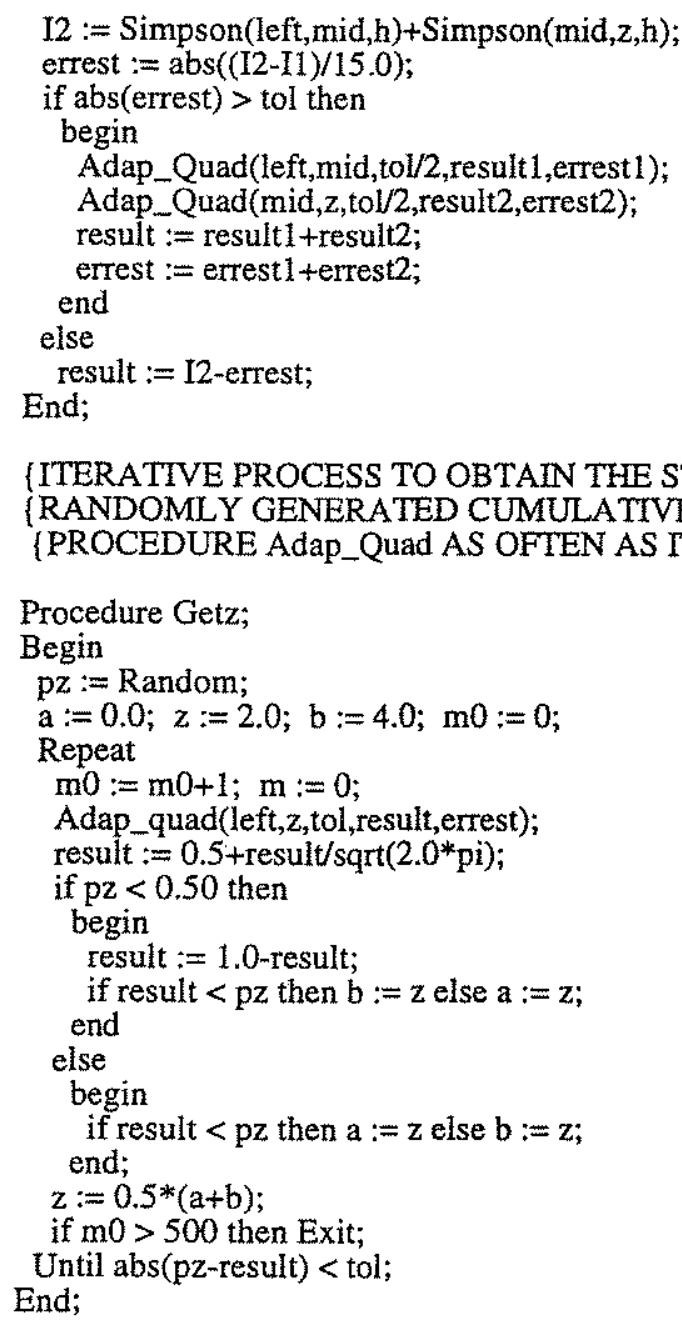

\{FUNCTION DETERMINES PREDICTED BOND FORCE\}

Function Eqn 1: Real;

Var Eq : Real;

Begin

Eq := $\left(63.0 * \mathrm{Ls}^{*}(\mathrm{Cmin}+0.5 * \mathrm{Db})+2130.0 * \mathrm{Ab}\right) *(0.10 * \mathrm{CMm}+0.90)$;

Eqn $1:=\operatorname{Sqrt}(\operatorname{Sqrt}(\mathrm{fc}))^{*}$ Eq

End;

\{FUNCTION DETERMINES NOMINAL BOND FORCE) 
Function Eqn 2: Real;

Var Eq : Real;

Begin

$\mathrm{Eq}:=(63.0 * \mathrm{Ls} *(\mathrm{Cmind}+0.5 * \mathrm{Db})+2130.0 * \mathrm{Ab})$

Eqn2 := Sqrt(Sqrt(fc) $) * E q$

End;

\{FUNCTION DETERMNES THE APPROPRIATE VALUES FOR SOME PARAMETERS\} \{AND FUNCTIONS USED IN THE DETERMINATION OF BOND FORCE\}

Function Eqn(n:Byte) : Real;

Begin

Csi $:=(0.5 * \mathrm{~W}-\mathrm{Nb} * \mathrm{Db}-\mathrm{Cso}) /(\mathrm{Nb}-1.0)$;

Cs := Min(Cso,Csi+0.25);

Cmin := $\mathrm{Min}(\mathrm{Cs}, \mathrm{Cb})$;

Cmind :=min(min(Cso,Csi),Cb);

$\mathrm{Cmax}:=\operatorname{Max}(\mathrm{Cs}, \mathrm{Cb})$

$\mathrm{CMm}:=\mathrm{Cmax} / \mathrm{Cmin}$

if $\mathrm{CMm}>3.5$ then $\mathrm{CMm}:=3.5$;

if $\mathrm{n}=1$ then Eqn $:=$ Eqn 1

else Eqn $;=$ Eqn2;

End;

(PROCEDURE FOR READING, FROM THE DATA FILE, AND DISPLAYING, ON THE\} [SCREEN, THE NOMINAL VALUES FOR EACH BEAM]

Procedure InputData;

Begin

readin(fin, $\mathrm{W}, \mathrm{h}, \mathrm{fc}, \mathrm{Cb}, \mathrm{Cso}, \mathrm{Ls}, \mathrm{Nb}, \mathrm{Db}, \mathrm{Ab}$ );

$\mathrm{n}:=1+\mathrm{n}$

writeln('

writeln('

writeln('

writeln('

writeln'

writeln'

writelnc

writeln'

writeln'

writeln ${ }^{\prime}$

writeln ${ }^{\prime}$

writeln'

CURRENT INPUT DATA FROM FILE ',fname+'.DAT');

Data for beam number ............. ', n:5);

Beam width (ins.) .................., 'W:5:2);

Beam depth (ins.) ............... ', h:5:2);

Concrete strength (psi) ..........', ,fc:4:0);

Concrete cover (ins.) ........... ', $\mathrm{Cb}: 5: 3$ );

Concrete side cover (ins.) ....... ', Cso:5:3);

Splice length (ins.) ............ ',Ls:5:2);

Number of bars spliced ..........', $, \mathrm{Nb}: 2$ );

Spliced bar diameter (ins.) ..... ', Db:5:3);

End;

Spliced bar area (sq. ins.) ..... ',Ab:4:2);

\{PROCEDURE FOR WRITING THE NOTATION AND HEADING INFORMATION FOR\} [EACH BEAM INTO THE OUTPUT FILE FOR THE BEAM]

Procedure OutData;

Begin

writeln(fout,' RESULTS OUTPUT FOR BEAMS W/O STIRRUPS');

writeln(fout,' -..-.-.-.');

writeln(fout, $\quad \mathrm{n}=$ Number of iterations');

writeln(fout,' $\quad \mathrm{W}=$ Beam width (ins.)');

writeln(fout, $\quad \mathrm{fc}=$ Concrete strength (psi)');

writeln(fout, $\quad \mathrm{Cb}=$ Concrete cover (ins.)');

writeln(fout,' Cso $=$ Concrete side cover (ins.)');

writeln(fout, $\quad$ Csi $=$ One-half clear bar spacing (ins. $\left.)^{\prime}\right)$;

writeln(fout,' Ls = Splice length (ins.)');

writeln(fout, $\quad \mathrm{Nb}=$ Number of bars spliced');

writein(fout, $\quad \mathrm{Db}=$ Spliced bar diameter (ins.)');

writeln(fout,' $\quad A b=$ Spliced bar area (sq. ins.)');

writeln(fout,' ');

write(fout,' $n$ W fc $\mathrm{Cb}$ Cso Csi Ls $\mathrm{Nb}$ Db Ab ');

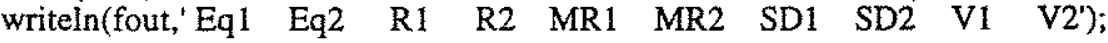


write(fout,'

writeln(fout,

End;

\{ITERATIVE PROCESS FOR DETERMINING THE LONG-TERM IN-SITU\}

\{COMPRESSIVE STRENGTH OF CONCRETE\}

Procedure fcstrR;

Var fc35: Real;

Begin

fc35:= fc;

Repeat

$\mathrm{fcR}:=\mathrm{fc}$;

fc $:=f c 35 *(0.89 *(1.0+0.08 * \ln (\mathrm{fcR} / 3600) / \ln (10.0)))$;

until $\mathrm{Abs}(\mathrm{fcR}-\mathrm{fc})<1.0$;

End;

\{MAIN PROCEDURE FOR THE MONTE CARLO SIMULATIONS WHERE THE DATA\}

\{FOR EACH BEAM IS READ FROM THE DATA FILE; RUNS ALL THE PROCEDURES\}

\{REQUIRED FOR THE SIMULATIONS; COMPUTES THE MEANS, STANDARD\}

[DEVIATIONS, AND COV FOR EACH BEAM; COMPUTES THE CUMULATTVE)

\{MEANS, STANDARD DEVIATIONS, AND COV; AND WRITES THE RESULTS\}

[INTO FILES

Procedure Simulate;

Begin

\{WRITES THE NOTATION AND HEADING INFORMATION FOR \}

\{MONTE CARLO SIMULATION OUTPUT RESULT FILE\}

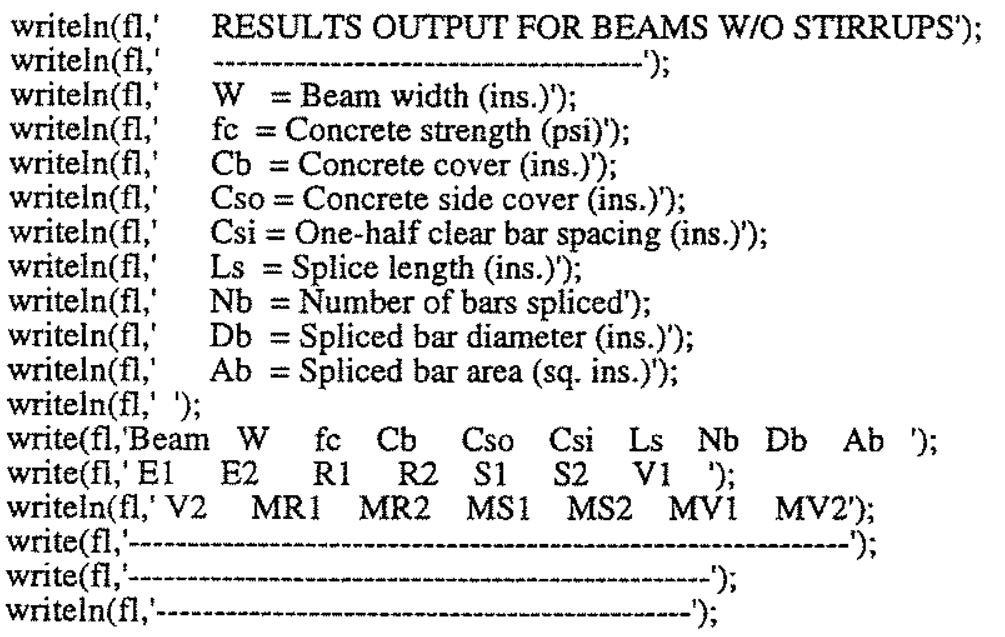

[READS THE FIRST LINE (HEADING) FROM THE INPUT FILE)

readin(fin,st);

\{INITIALIZES VARIABLES\}

$\mathrm{mr} 1:=0.0 ; \mathrm{mr} 2:=0.0 ; \mathrm{ms} 1:=0.0 ; \mathrm{ms} 2:=0.0 ; \mathrm{mv} 1:=0.0 ; \mathrm{mv} 2:=0.0 ;$

$\mathrm{s} 1:=0.0 ; \mathrm{s} 2:=0.0 ; \mathrm{k} 1:=0 ; \mathrm{s} 3:=0.0 ; \mathrm{s} 4:=0.0$

\{TTERATION FOR READING AND PROCESSING THE DATA FOR EACH BEAM\}

While not Eof(fin) do

begin

Window $(1,1,80,25)$;

ClrScr; InputData; Str(n,st);

Assign(fout,fname+.'+st); $\{\$ 1-\}$ Rewrite(fout); $\{\$ 1+\}$ 
Chkfile('FILE FOR OUTPUT','DISK/DRIVE');

if err $=1$ then Exit;

[INITLALIZES AND EVALUATES VARIABLES\}

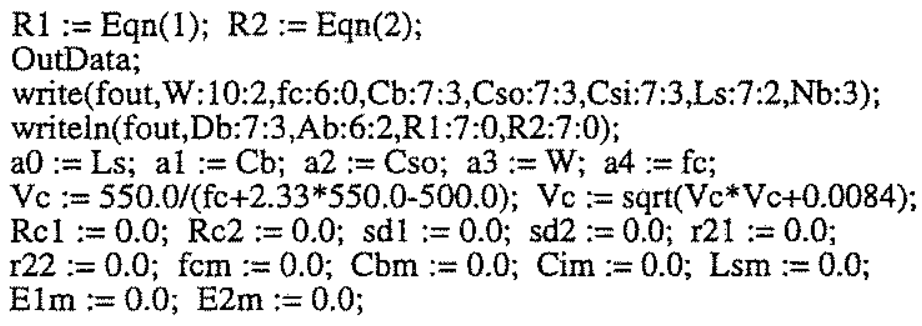

\{ITERATION FOR PERFORMING THE MONTE CARLO SIMULATIONS $k$ TIMES\} \{FOR EACH BEAM\}

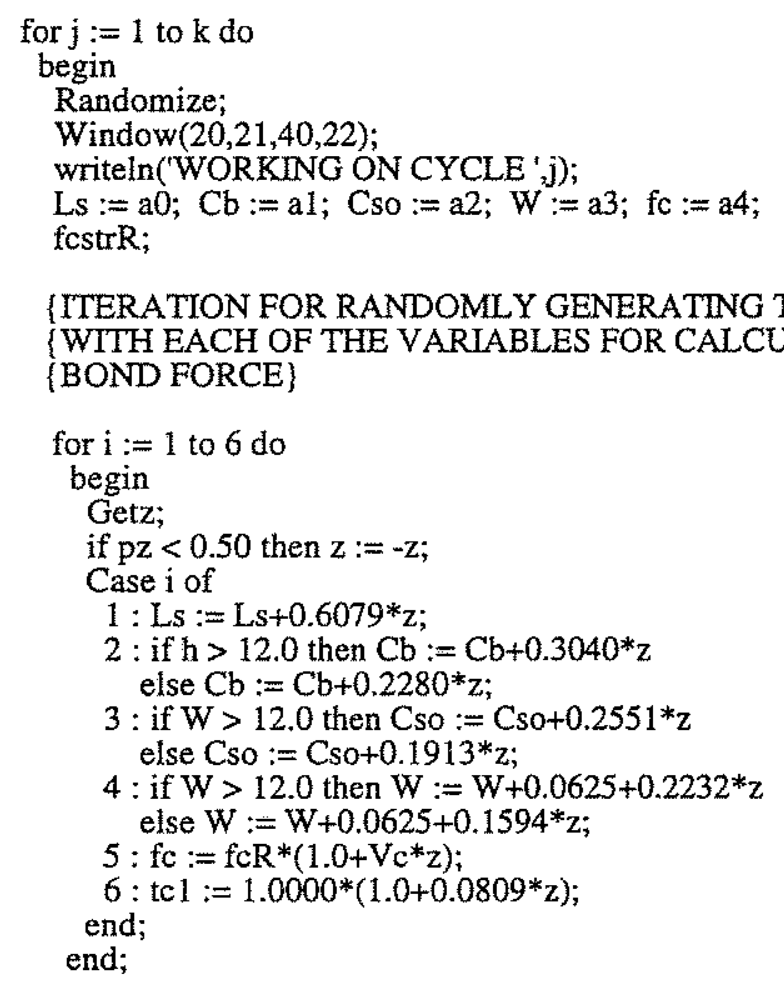

\{COMPUTES THE MEAN, STANDARD DEVIATION, AND COV FOR\} \{EACH BEAM AND CUMULATTVE MEAN, STANDARD DEVIATION\} \{AND COV INCLUDING PRECEDING BEAMS\}

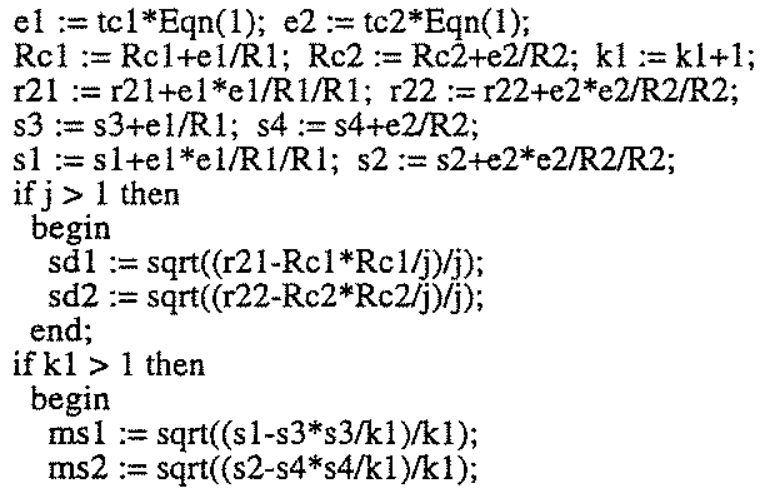


end;

$\mathrm{fcm}:=\mathrm{fcm}+\mathrm{fc} ; \mathrm{Cbm}:=\mathrm{Cbm}+\mathrm{Cb} ; \mathrm{Cim}:=\mathrm{Cim}+\mathrm{Csi} ; \mathrm{Lsm}:=\mathrm{Lsm}+\mathrm{Ls} ;$

$\mathrm{E} 1 \mathrm{~m}:=\mathrm{E} 1 \mathrm{~m}+\mathrm{e} 1 ; \mathrm{E} 2 \mathrm{~m}:=\mathrm{E} 2 \mathrm{~m}+\mathrm{e} 2$

[SECTION DISPLAYS THE CURRENT RESULTS ON THE SCREEN\}

Window $(10,16,70,21)$;

writeln(' CURRENT R1 = ',e1/R1:6:3,' CURRENT R2 = ',e2/R2:6:3);

writeln(' MEAN R1 = ',Rc1/j:6:3,' MEAN R2 = ',Rc2/j:6:3);

writeln(' STD DEV 1 = ',sd1:6:3,' STD DEV 2 = ',sd2:6:3);

writeln(' C.O.V. $1=$ ',sd1/Re1*j:6:3,' C.0.V. $2={ }^{\prime}$, sd2/Rc2*j:6:3);

\{WRITES THE CURRENT RESULTS INTO THE RESULT FILE FOR\}

\{EACH BEAM\}

write(fout,j:3,W:7:2,fc:6:0,Cb:7:3,Cso:7:3,Csi:7:3,Ls:7:2,Nb:3,Db:7:3,Ab:6:2);

write(fout,e1:7:0,e2:7:0,e1/R1:7:3,e2/R2:7:3,Rc1/j:7:3,Rc2/j:7:3,sd1:7:3);

writeln(fout,sd2:7:3,sd1/Rc1*j:7:3,sd2/Rc2*j:7:3);

end;

writeln(fout,' ');

Close(fout);

\{COMPUTES THE AVERAGE VALUES FOR ALL VARIABLES FOR\}

\{EACH OF THE BEAMS\}

$\mathrm{fc}:=\mathrm{fcm} / \mathrm{j} ; \mathrm{Cb}:=\mathrm{Cbm} / \mathrm{j} ; \mathrm{Csi}:=\mathrm{Cim} / \mathrm{j} ; \mathrm{Ls}:=\mathrm{Lsm} / \mathrm{j} ;$ el $:=\mathrm{E} 1 \mathrm{~m} / \mathrm{j} ;$

$\mathrm{e} 2:=\mathrm{E} 2 \mathrm{~m} / \mathrm{j} ; \mathrm{mr} 1:=\mathrm{mr} 1+\mathrm{e} 1 / \mathrm{R} 1 ; \mathrm{mr} 2:=\mathrm{mr} 2+\mathrm{e} 2 / \mathrm{R} 2 ; \mathrm{mv} 1:=\mathrm{ms} 1 / \mathrm{mr} 1 * \mathrm{n}$;

$\mathrm{mv} 2:=\mathrm{ms} 2 / \mathrm{mr} 2 * \mathrm{n}$;

\{WRITES THE CURRENT BEAM RESULTS INTO THE RESULT FILE\}

(THAT CONTAINS THE SUMMARY OF ALL THE RESULTS FOR ALL BEAMS)

write(fl,n:3,W:7:2,fc:6:0, Cb:7:3,Cso:7:3,Csi:7:3,Ls:7:2,Nb:3,Db:7:3);

write(fl,Ab:6:2,e1:7:0,e2:7:0,e1/R1:7:3,e2/R2:7:3);

write(fl,sd1:7:3,sd2:7:3,sd1/Rc1*j:7:3,sd2/Rc2*j:7:3, mr1/n:7:3);

writeln(fl,mr2/n:7:3,ms 1:7:3,ms2:7:3, mv1:7:3,mv2:7:3);

End; end;

\{CHECKS TO SEE IF A SPECIFIED FILE EXISTS OR WAS OPENED SUCCESSFULLY\}

Procedure Chkfile(s1,s2 : String);

Begin

if Ioresult $>0$ then

begin

Window $(10,10,70,15)$;

ClrScr;

writeln(' CANNOT OPEN ',s1);

writeln;

writeln(' PRESS ANY KEY TO END AND CHECK ',s2);

err $:=1$.

st := Readkey;

Exit;

End;

\{START OF THE MAIN PROGRAM WHERE ALL INPUT IS MADE\}

BEGIN

GetTime(hr,mn,sec,sec 100);

Window $(1,1,80,25)$;

ClrScr;

err $:=0$

$\mathrm{n}:=0$

write(' ENTER NAME OF THE DATA FILE W/O EXTENSION : '); 
readln(fname);

Assign(fin,fname+'.DAT');

(\$I-) Reset(fin); $\{$ II+\}

Chkfile('DATA FILE','DATA FILE');

if $\mathrm{err}=1$ then Exit;

Assign(fl,fname+'.RST);

\{\$I- Rewrite(fl); $\$$ I + \}

Chkfile('FILE FOR OUTPUT',DISK/DRIVE');

if $\mathrm{err}=1$ then Exit;

writeln;

write(' ENTER THE NUMBER OF CYCLES REQUIRED : '); readln(k);

Simulate;

GetTime (hr1,mn1,sec1,sec1001);

writeln(fl,' ');

writeln(fl,'STOPPING TIME : ',hrl,':',mn1,':, sec1,',',sec1001);

writeln(fl,'STARTTNG TMME : ',hr,':',mn,':',sec,':,sec100);

Close(fin);

Close(fl);

END. 
(b)

Program Bst;

\{MONTE CARLO SIMULATION FOR BEAMS WITH STIRRUPS\}

Uses Crt, Dos;

[DECLARATION OF GLOBAL CONSTANTS FOR THE PROGRAM]

Const

left $=0.0 ;$ tol $=1.0 \mathrm{e}-6$;

[DECLARATION OF GLOBAL VARIABLES FOR THE PROGRAM]

$\operatorname{Var}$

$\mathrm{a}, \mathrm{b}, \mathrm{z}, \mathrm{pz}, \mathrm{Ls}, \mathrm{Cb}, \mathrm{Csi}, \mathrm{fc}, \mathrm{Db}, \mathrm{Ab}, \mathrm{Cmin}, \mathrm{Cmax}, \mathrm{fcm}, \mathrm{Cbm}, \mathrm{Cim}, \mathrm{Lsm}$, E1m, E2m, R1, R2, h, tc1, tc2, Rc1, Rc2, a0, a1, a2, a3, a4, sd1, s1, $\mathrm{sd} 2, \mathrm{r} 21, \mathrm{r} 22$, Vc, Av, Sv, Nv, mr1, mr2, ms1, ms2, mv1, mv2, s2, s3, result, errest, Cso, W, Cs, s4, Atr, Atm, e1, e2, e11, e12, e21, e22,

$\mathrm{CMm}$, fcR, Rr, as, Vr, Rm, Rm, Cmind, deno1, deno2, trtd: Real;

$\mathrm{Nb}, \mathrm{Ns}$, err : Byte;

$\mathrm{n}, \mathrm{I}:$ Integer;

$\mathrm{k} 1, \mathrm{i}, \mathrm{j}, \mathrm{k}, \mathrm{m}, \mathrm{m0}, \mathrm{hr}, \mathrm{mn}, \mathrm{sec}, \mathrm{sec} 100, \mathrm{hr} 1, \mathrm{mn} 1, \sec 1, \sec 1001$ : Word;

fname : String[20];

st : String;

fin, fout, fl : Text;

\{FUNCTION EVALUATES THE EXPRESSION $\mathrm{e}^{\wedge}-\left(0.5^{*} \mathrm{Z}^{\wedge} 2\right)$ \}

Function $\mathrm{F}(\mathrm{z}:$ Real $)$ : Real;

Begin

$F:=\exp \left(-z^{*} z / 2.0\right)$;

End;

\{FUNCTION EVALUATES THE EXPRESSION FOR SIMPSON'S RULE\}

Function Simpson(a,b,h : Real) : Real;

Var mid : Real;

begin

mid : $=(b+a) / 2.0$;

Simpson $:=\mathrm{h} / 6.0^{*}\left(\mathrm{~F}(\mathrm{a})+4.0^{*} \mathrm{~F}(\mathrm{mid})+\mathrm{F}(\mathrm{b})\right)$;

end;

[NUMERICAL METHOD TO DETERMINE THE CURRENT IMPROVED STANDARD\}

\{NORMAL VALUE, $z[i+1]$, FROM A PREVIOUS VALUE OF $z$ [i] DURING EACH CYCLE\}

\{OF THE TTERATTVE PROCESS\}

Procedure Adap_Quad(left,z,tol:Real; var result:Real; var errest:Real);

Var h, I1, I2, mid, result1, result2, errest1, errest2 : Real;

Begin

$\mathrm{m}:=\mathrm{m}+1$

$\mathrm{h}:=\mathrm{z}$-left;

I1 := Simpson(left,z,h);

$h:=h / 2.0$;

mid $:=(\operatorname{left}+\mathrm{z}) / 2.0$;

I2 := Simpson(left,mid,h)+Smpson(mid,z,h);

errest $:=\operatorname{abs}((\mathrm{I} 2-\mathrm{H} 1) / 15.0)$;

if $a b s$ (errest) $>$ tol then

begin

Adap_Quad(left,mid,tol/2,result1,errest1);

Adap_Quad(mid,z,tol/2,result2,errest2);

result $:=$ result $1+$ result 2 ;

errest $:=$ errest $1+$ errest 2 ;

end 


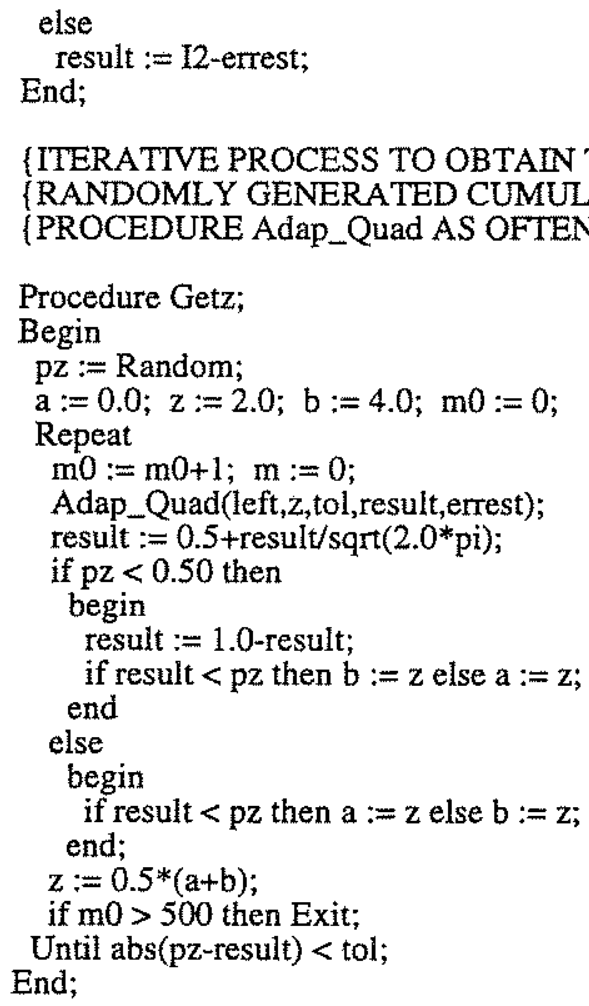

\{FUNCTION DETERMINES THE MINIMUM OF TWO VARIABLES\}

Function Min $(a, b:$ Real $):$ Real;

begin

if $\mathrm{a}<\mathrm{b}$ then Min $:=\mathrm{a}$

else Min := b;

end;

\{FUNCTION DETERMINES THE MAXIMUM OF TWO VARIABLES\}

Function Max $(\mathrm{a}, \mathrm{b}:$ Real $):$ Real;

begin

if $a>b$ then $M a x:=a$

else Max :=b;

end;

\{FUNCTION DETERMINES NOMINAL BOND FORCE WITH THE Cmax/Cmin TERM\}

Function Eqn 1 : Real;

Var Eq : Real;

Begin

$\mathrm{Eq}:=80.2 * \mathrm{Ls}^{*} \mathrm{Ab} / \mathrm{Db} *$ denol $+2130.0^{*} \mathrm{Ab} *\left(0.10^{*} \mathrm{CMm}+0.90\right)$;

Eqn1 $:=\operatorname{Sqrt}(\operatorname{Sqrt}(\mathrm{fc})) * \mathrm{Eq}$

End;

\{FUNCTION DETERMINES NOMINAL BOND FORCE WITHOUT THE\}

\{Cmax/Cmin TERM\}

Function Eqn2 ; Real;

Var Eq : Real;

Begin

$\mathrm{Eq}:=80.2 * \mathrm{~L} \mathrm{~s}^{*} \mathrm{Ab} / \mathrm{Db} \mathrm{b}^{*}$ deno2+2130.0*Ab;

Eqn2 := Sqrt(Sqrt(fc) $) * E q$

End; 
\{FUNCTION DETERMINES PREDICTED BOND FORCE\}

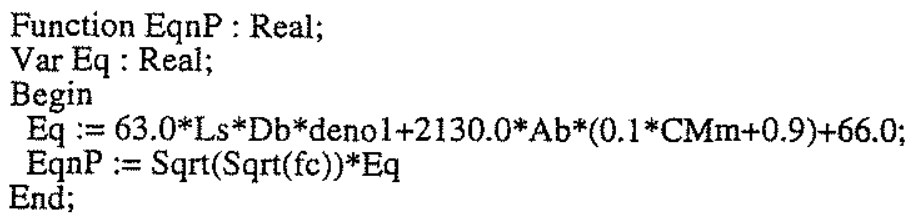

\{FUNCTION DETERMINES THE APPROPRIATE VALUES FOR SOME PARAMETERS\} \{AND FUNCTIONS USED IN THE DETERMINATION OF BOND FORCE\}

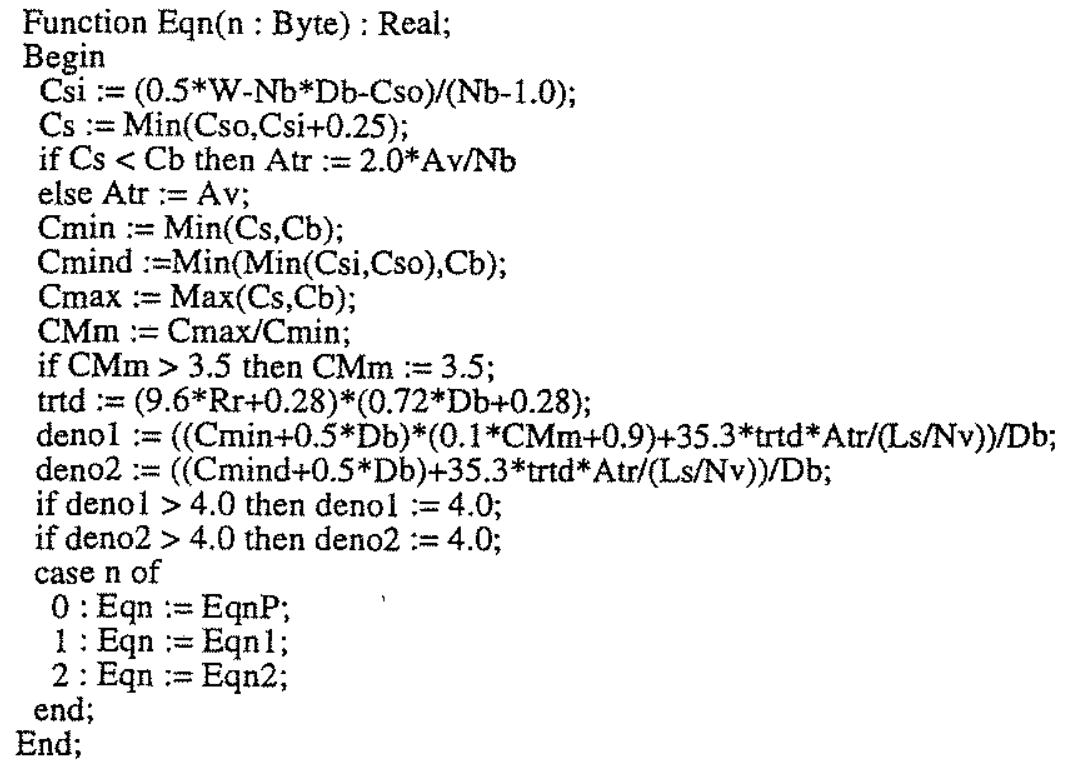

\{PROCEDURE FOR READING, FROM THE DATA FILE, AND DISPLAYING, ON THE\} \{SCREEN, THE NOMINAL VALUES FOR EACH BEAM]

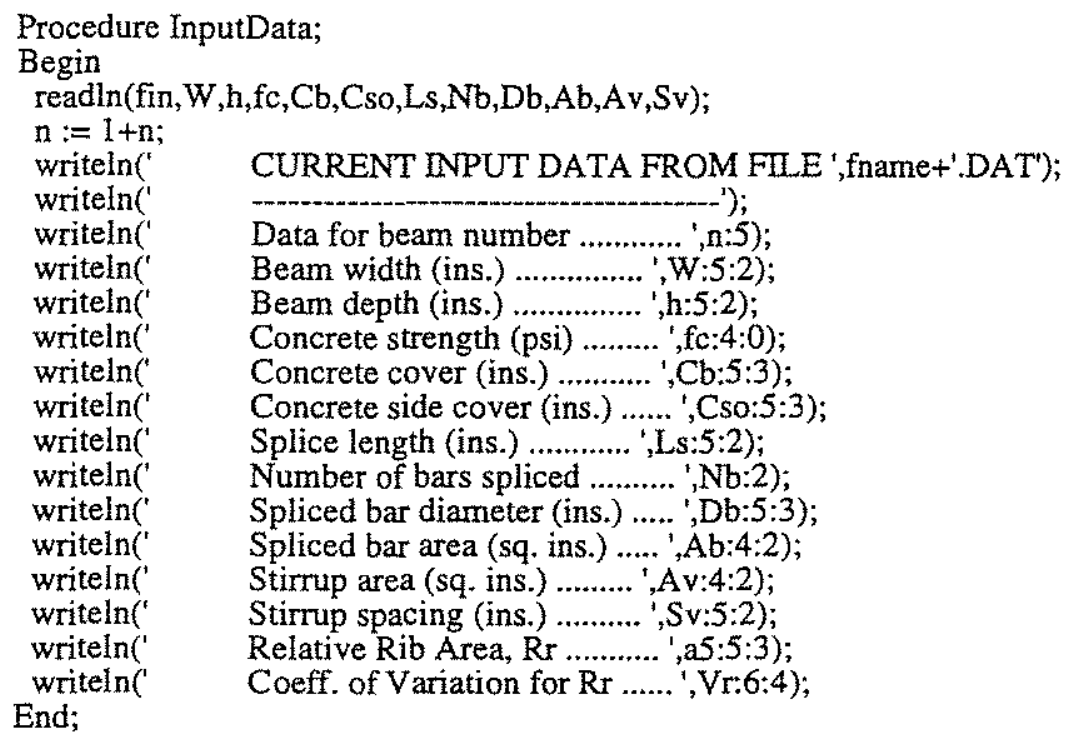

\{PROCEDURE FOR WRITING THE NOTATION AND HEADING INFORMATION FOR\} \{EACH BEAM INTO THE OUTPUT FILE FOR THE BEAM]

Procedure OutData; Begin 


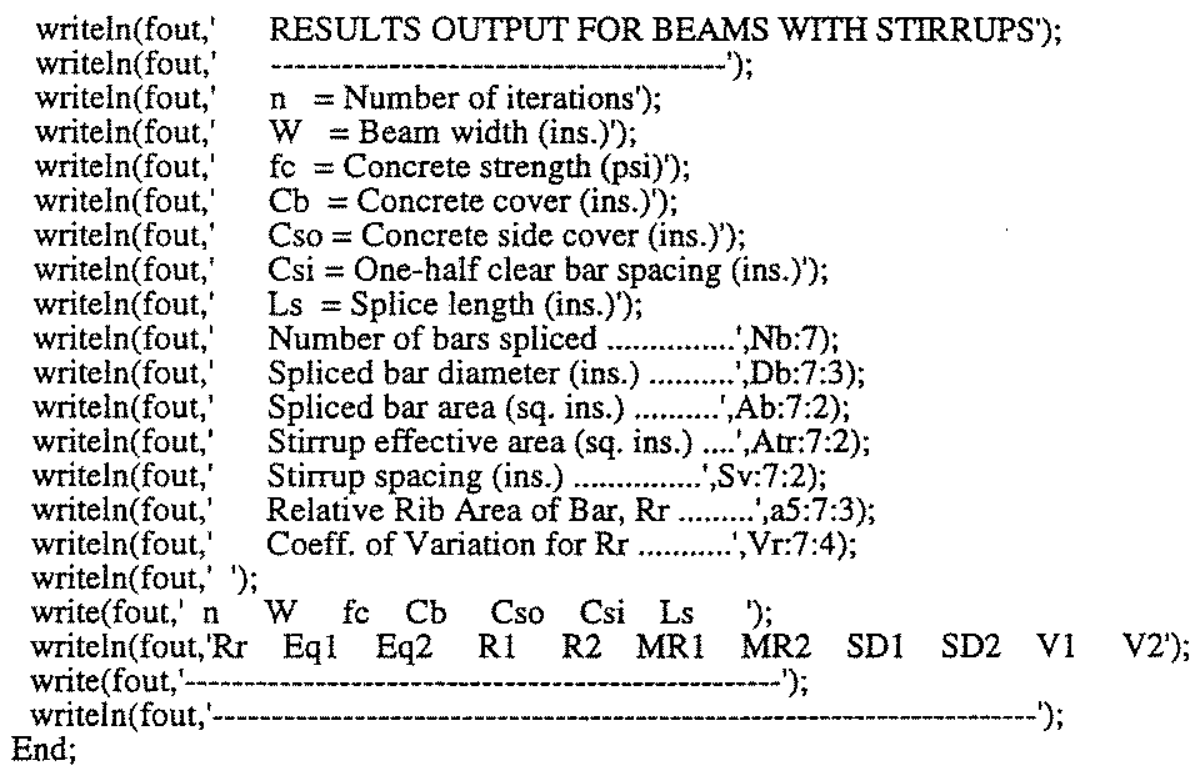

\{TTERATIVE PROCESS FOR DETERMINING THE LONG-TERM IN-SITU) \{COMPRESSIVE STRENGTH OF CONCRETE\}

Procedure fcstrR;

Var fc35 : Real;

Begin

$\mathrm{fc} 35:=\mathrm{fc}$;

Repeat

$\mathrm{fcR}:=\mathrm{fc} ;$

fc $:=f c 35 *(0.89 *(1.0+0.08 * \ln (f c R / 3600) / \ln (10.0)))$

until $\mathrm{Abs}(\mathrm{fcR}-\mathrm{fc})<1.0$;

End;

\{MAIN PROCEDURE FOR THE MONTE CARLO SIMULATIONS WHERE THE DATA\}

\{FOR EACH BEAM IS READ FROM THE DATA FILE; RUNS ALL THE PROCEDURES\}

\{REQUIRED FOR THE SIMULATIONS; COMPUTES THE MEANS, STANDARD\}

\{DEVIATIONS, AND COV FOR EACH BEAM; COMPUTES THE CUMULATIVE\}

(MEANS, STANDARD DEVIATIONS, AND COV; AND WRITES THE RESULTS\}

\{INTO FILES \}

Procedure Simulate;

Begin

\section{[WRTTES THE NOTATION AND HEADING INFORMATION FOR [MONTE CARLO SIMULATION OUTPUT RESULT FILE]}

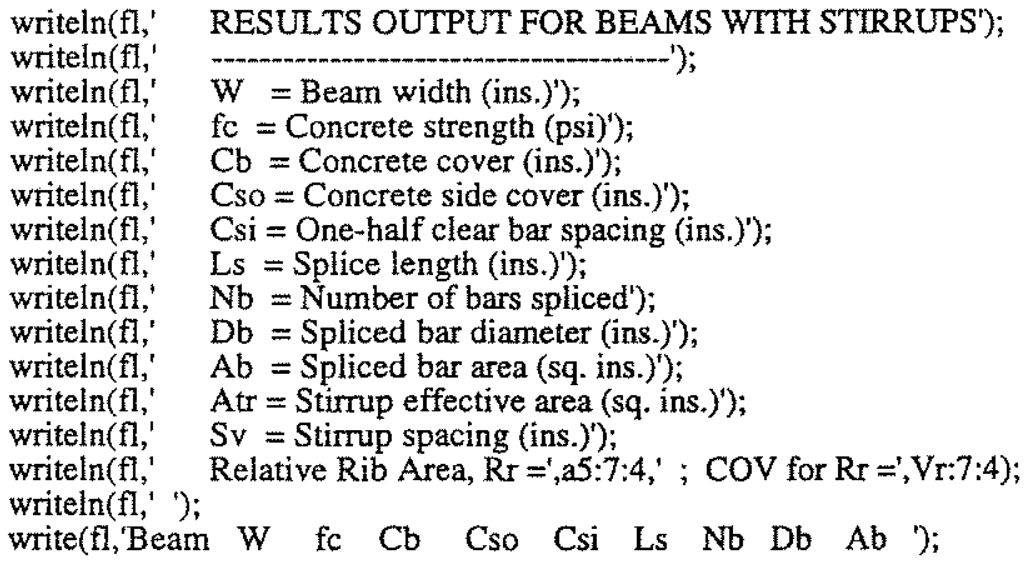




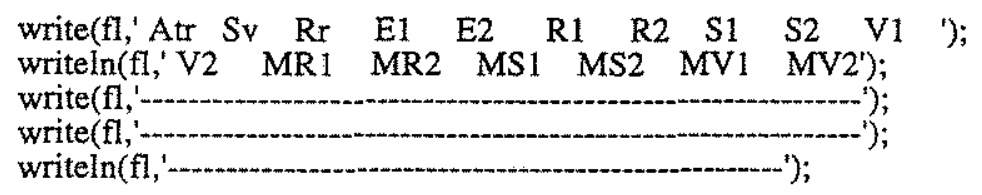

[READS THE FIRST LINE, HEADING, FROM THE INPUT FILE]

readln(fin,st);

\section{\{NITLALIZES VARIABLES\}}

$\mathrm{mr} 1:=0.0 ; \mathrm{mr} 2:=0.0 ; \mathrm{ms} 1:=0.0 ; \mathrm{ms} 2:=0.0 ; \mathrm{mv} 1:=0.0 ; \mathrm{mv} 2:=0.0 ;$ $\mathrm{s} 1:=0.0 ; \mathrm{s} 2:=0.0 ; \mathrm{k} 1:=0 ; \mathrm{s} 3:=0.0 ; \mathrm{s} 4:=0.0$;

\section{\{ITERATION FOR READING AND PROCESSING THE DATA FOR EACH BEAM\}}

While not Eof(fin) do

begin

Window $(1,1,80,25)$;

ClrScr; InputData; Str(n,st);

Assign(fout,fname +'.'tst); \{\$I- $\mid$ Rewrite(fout); $\$$ II+\}

Chkfile('FILE FOR OUTPUT','DISK/DRIVE');

if err = 1 then Exit;

\section{\{INITIALIZES AND EVALUATES VARIABLES\}}

$\mathrm{Rr}:=\mathrm{a} 5 ; \mathrm{Nv}:=\mathrm{Ls} / \mathrm{Sv} ; \mathrm{R} 1:=\mathrm{Eqn}(1) ; \mathrm{R} 2:=\mathrm{Eqn}(2) ;$

OutData;

write(fout,W:11:2,fc:6:0,Cb:7:3,Cso:7:3,Csi:7:3,Ls:7:2);

writeln(fout, Rr:7:4,R1:7:0,R2:7:0);

$\mathrm{a} 0:=\mathrm{Ls} ;$ a1 $:=\mathrm{Cb} ; \mathrm{a} 2:=\mathrm{Cso} ; \mathrm{a} 3:=\mathrm{W} ; \mathrm{a} 4:=\mathrm{fc}$;

$\mathrm{Vc}:=550.0 /(\mathrm{fc}+2.33 * 550.0-500.0) ; \mathrm{Vc}:=\mathrm{sqrt}(\mathrm{Vc} * \mathrm{Vc}+0.0084) ;$

fcstrR:

$\mathrm{Rc} 1:=0.0 ; \mathrm{Rc} 2:=0.0 ; \mathrm{sd} 1:=0.0 ; \mathrm{sd} 2:=0.0 ; \mathrm{r} 21:=0.0$;

$\mathrm{r} 22:=0.0 ; \mathrm{fcm}:=0.0 ; \mathrm{Cbm}:=0.0 ;$ Cim $:=0.0 ; \mathrm{Lsm}:=0.0$;

$\mathrm{E} 1 \mathrm{~m}:=0.0 ; \mathrm{E} 2 \mathrm{~m}:=0.0 ; \mathrm{Atm}:=0.0 ;$ Rrm $:=0.0$;

\{ITERATION FOR PERFORMING THE MONTE CARLO SIMULATIONS $\mathrm{k}$ TIMES\} \{FOR EACH BEAM)

for $j:=1$ to $k$ do

begin

Randomize;

Window $(20,23,40,24)$;

writeln('WORKING ON CYCLE',j);

Ls : $=\mathrm{a} 0 ; \mathrm{Cb}:=\mathrm{a} 1 ;$ Cso $:=\mathrm{a} 2 ; \mathrm{W}:=\mathrm{a} 3 ; \mathrm{fc}:=\mathrm{a} 4 ; \mathrm{Rr}:=\mathrm{a} 5+\mathrm{Rm}$;

\{ITERATION FOR RANDOMLY GENERATING THE VARIABILITY ASSOCIATED\} \{WTTH EACH OF THE VARIABLES FOR CALCULATING THE PREDICTED\} \{BOND FORCE\}

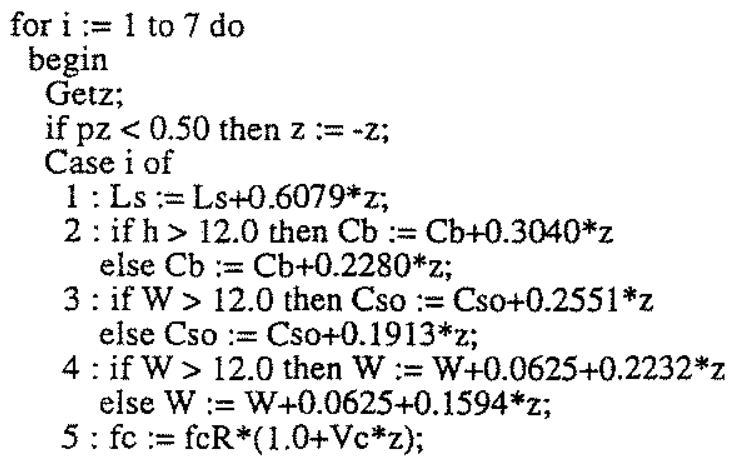




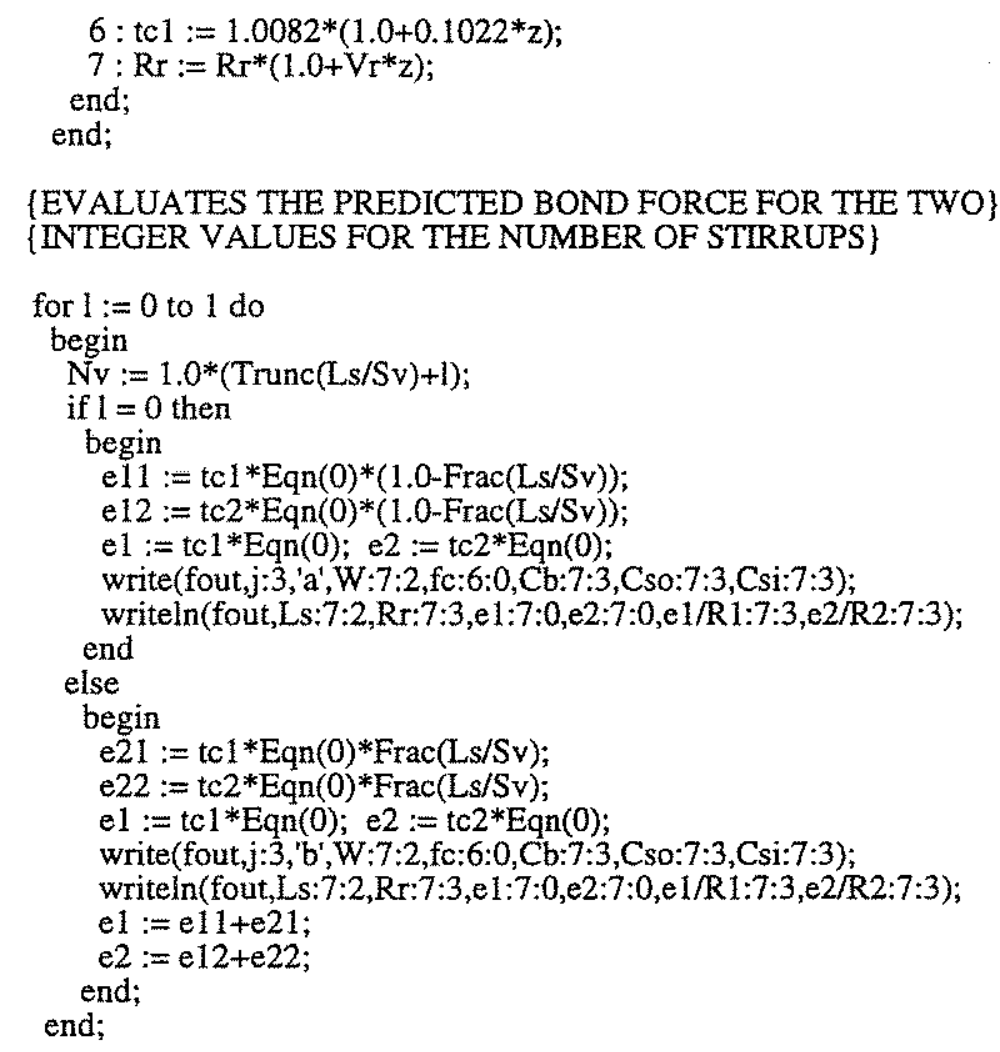

(COMPUTES THE MEAN, STANDARD DEVIATION, AND COV FOR \} \{EACH BEAM AND CUMULATIVE MEAN, STANDARD DEVIATION,\} \{AND COV INCLUDING PRECEDING BEAMS \}

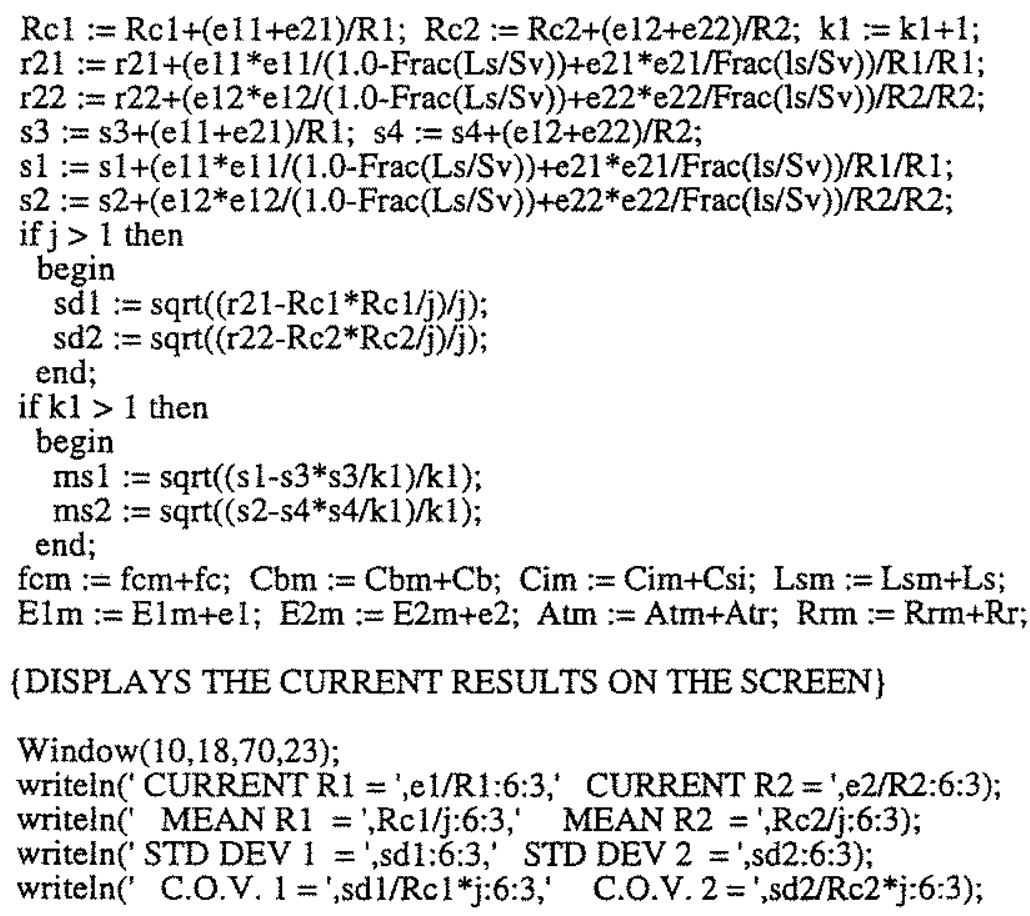

(WRITES THE CURRENT RESULTS INTO THE RESULT FILE FOR) \{EACH BEAM\} 
write(fout, $\mathrm{j}: 3, \mathrm{~W}: 8: 2, \mathrm{fc}: 6: 0, \mathrm{Cb}: 7: 3, \mathrm{Cso}: 7: 3, \mathrm{Csi}: 7: 3, \mathrm{Ls}: 7: 2, \mathrm{Rr}: 7: 3$ );

write(fout,e1:7:0,e2:7:0,e1/R1:7:3,e2/R2:7:3,Rc1/j:7:3,Rc2/j:7:3,sd1:7:3);

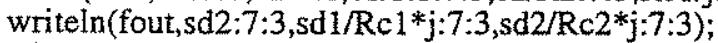

end;

writeln(fout,' ');

Close(fout);

\{COMPUTES THE AVERAGE VALUES FOR ALL VARIABLES FOR \}

\{EACH OF THE BEAMS \}

fc $:=\mathrm{fcm} / \mathrm{j} ; \mathrm{Cb}:=\mathrm{Cbm} / \mathrm{j} ; \mathrm{Csi}:=\mathrm{Cim} / \mathrm{j} ; \mathrm{Ls}:=\mathrm{Lsm} / \mathrm{j} ;$ el $:=\mathrm{E} 1 \mathrm{~m} / \mathrm{j} ;$

$\mathrm{e} 2:=\mathrm{E} 2 \mathrm{~m} / \mathrm{j} ; \mathrm{mr} 1:=\mathrm{mr} 1+\mathrm{e} 1 / \mathrm{R} 1 ; \mathrm{mr} 2:=\mathrm{mr} 2+\mathrm{e} 2 / \mathrm{R} 2 ; \mathrm{mv} 1:=\mathrm{ms} 1 / \mathrm{mr} 1{ }^{*} \mathrm{n}$;

$\mathrm{mv} 2:=\mathrm{ms} 2 / \mathrm{mr} 2 * \mathrm{n} ;$ Atr $:=A t m / j ; \operatorname{Rr}:=\mathrm{Rrm} / \mathrm{j}$;

\{WRITES THE CURRENT BEAM RESULTS INTO THE RESULT FULE\}

\{THAT CONTAINS THE SUMMARY OF ALL THE RESULTS FOR ALL BEAMS\}

write(fl,n:3,W:7:2,fc:6:0,Cb:7:3,Cso:7:3,Csi:7:3,Ls:7:2,Nb:3,Db:7:3);

write(fl,Ab:6:2,Atr:6:2,Sv:6:1,Rr:7:3,e1:7:0,e2:7:0,e1/R1:7:3,e2/R2:7:3);

write(fl,sd1:7:3,sd2:7:3,sd1/Rc1*j:7:3,sd2/Rc2*j:7:3,mr1/n:7:3);

writeln(fl,mr2/n:7:3,ms1:7:3,ms2:7:3,mv1:7:3,mv2:7:3);

End; end;

\{CHECKS TO SEE IF A SPECIFIED FILE EXISTS OR WAS OPENED SUCCESSFULLY\}

Procedure Chkfile(s1,s2: String);

Begin

if Ioresult $<>0$ then

begin

Window $(10,10,70,15)$;

ClrScr;

writeln(' CANNOT OPEN',s1);

writeln;

writeln(' PRESS ANY KEY TO END AND CHECK 's2);

err $:=1$

st := Readkey;

Exit;

End;

\{START OF THE MAIN PROGRAM WHERE ALL INPUT IS MADE\}

BEGIN

GetTime(hr,mn,sec,sec100);

Window $(1,1,80,25)$;

$\mathrm{ClrScr}$

err $:=0$

$\mathrm{n}:=0$

write(' ENTER NAME OF THE DATA FILE W/O EXTENSION : ');

readln(fname);

Assign(fin,fname+'.DAT');

\{\$I- Reset(fin); $\{$ I +$\}$

Chkfile('DATA FILE ',DATA FILE');

if err $=1$ then Exit;

Assign(fl,fname+',RST");

$\{\$ \mathrm{I}-\}$ Rewrite(fI); $\{\mathbf{I I}+\}$

Chkfile('FILE FOR OUTPUT', 'DISK/DRIVE');

if err $=1$ then Exit;

writeln;

write(' ENTER THE NUMBER OF CYCLES REQUIRED : '); readln(k);

writeln;

write(' ENTER THE RELATTVE RIB AREA OF BAR:'); readln(a5);

writeln;

write(' ENTER DEVIATION OF RELATIVE RIB AREA : '); readin(Rm); 
writeln;

write(' ENTER THE COV OF RELATIVE RIB AREA : '); readln(Vr);

Sirnulate;

GetTime(hr1,mn1,sec1,sec1001);

writeln(fl,' ');

writeln(fl,'STOPPING TTME : ',hr1, ',',mn1,':',sec1,',',sec1001);

writeln(fl,'STARTING TIME : ',hr,',',mn,',',sec,',',sec 100);

Close(fin);

Close(fl);

END. 


\section{Appendix C}

\section{Notation}

$$
\begin{aligned}
& \mathrm{A}_{\mathrm{b}} \quad=\text { bar area, in in.2 } \\
& \text { A } \quad=\text { influence area, in } \mathrm{ft}^{2} \\
& \mathrm{~A}_{\mathrm{T}} \quad=\text { tributary area, in } \mathrm{ft}^{2} \\
& \mathrm{~A}_{\mathrm{tr}}=\text { area of each stirrup or tie crossing the potential plane of splitting adjacent to the } \\
& \text { reinforcement being developed or spliced, in in. } 2 \\
& \text { b = beam width, in in. } \\
& \text { c } \quad=\left(c_{m}+0.5 d_{b}\right)\left(0.1 c_{M} / c_{m}+0.9\right) \text { or }\left(c_{m}+0.5 d_{b}\right) \\
& c_{b}=\text { bottom cover of reinforcing bars, in in. } \\
& \mathrm{c}_{\mathrm{M}} \quad=\text { maximum value of } \mathrm{c}_{\mathrm{s}} \text { or } \mathrm{c}_{\mathrm{b}}\left(\mathrm{c}_{\mathrm{M}} / \mathrm{c}_{\mathrm{m}} \leq 3.5\right) \text {, in in. } \\
& c_{\mathrm{m}} \quad=\text { minimum value of } \mathrm{c}_{\mathrm{s}} \text { or } \mathrm{c}_{\mathrm{b}}\left(\mathrm{c}_{\mathrm{M}} / \mathrm{c}_{\mathrm{m}} \leq 3.5\right) \text {, in in. } \\
& \mathrm{c}_{\mathrm{s}}=\min \left(\mathrm{c}_{\mathrm{si}}+0.25 \text { in., } \mathrm{c}_{\mathrm{so}}\right) \text { or } \min \left(\mathrm{c}_{\mathrm{si}}, \mathrm{c}_{\mathrm{so}}\right) \text {, in in. } \\
& \mathrm{c}_{\mathrm{si}} \quad=\text { one-half of clear spacing between bars, in in. } \\
& \mathrm{c}_{\text {so }}=\text { side cover of reinforcing bars, in in. } \\
& \mathrm{d}_{\mathrm{b}} \quad=\text { nominal bar diameter, in in. } \\
& \text { f } \quad=\text { stress rate, in } \mathrm{psi} / \mathrm{sec} \\
& \mathrm{f}_{\mathrm{c}}^{\prime} \quad=\text { concrete compressive strength, in psi; } \mathrm{f}_{\mathrm{c}}^{\prime}{ }^{1 / 4} \text { in psi } \\
& \mathrm{f}_{\mathrm{cf}}^{\prime} \quad=\text { concrete compressive strength at stress rate } \mathrm{f} \text {, in psi } \\
& \mathrm{f}_{\mathrm{cr}}^{\prime} \quad=\mathrm{f}_{\mathrm{c}}^{\prime}+2.33 \sigma_{\mathrm{ccyl}}-500 \mathrm{psi} \text {, required average concrete compressive strength, in psi } \\
& \mathrm{f}_{\mathrm{c} 35}^{\prime}=\text { concrete compressive strength at } \mathrm{f}=35 \mathrm{psi} / \mathrm{sec} \text {, in } \mathrm{psi} \\
& \mathrm{f}_{\mathrm{s}} \quad=\text { steel stress at failure, in psi } \\
& \mathrm{f}_{\mathrm{y}} \quad=\text { yield strength of bars being spliced or developed, in psi } \\
& \text { h = beam depth, in in. } \\
& \mathrm{K}_{\mathrm{tr}} \quad=35.3 \mathrm{t}_{\mathrm{r}} \mathrm{t}_{\mathrm{d}} \mathrm{A}_{\mathrm{tr}} / \mathrm{sn} \\
& \mathrm{L}_{\mathrm{O}} \quad=\text { basic } \text { (unreduced) live load } \\
& l_{d}=\text { development or splice length, in in. }
\end{aligned}
$$




$$
\begin{aligned}
& \mathrm{N} \quad=\text { number of transverse reinforcing bars (stimups or ties) crossing } l_{d} \\
& \mathrm{n} \quad=\text { number of bars being developed or spliced along the plane of splitting } \\
& \mathrm{n}_{\mathrm{b}} \quad=\text { number of bars } \\
& \mathrm{Q} \quad=\text { total load } \\
& \mathrm{QD}_{D} \quad=\text { random variable representing dead load effects } \\
& \mathrm{Q}_{\mathrm{Dn}} \quad=\text { nominal dead load } \\
& \mathrm{Q}_{\mathrm{L}} \quad=\text { random variable representing live load effects } \\
& \mathrm{Q}_{\mathrm{Ln}} \quad=\text { nominal live load } \\
& \left(\mathrm{Q}_{\mathrm{J}} / \mathrm{Q}_{\mathrm{D}}\right)_{\mathrm{n}}=\text { nominal ratio of live to dead load } \\
& \mathrm{q} \quad=\text { random loading } \\
& \mathrm{R}=\text { = random variable for resistance } \\
& \mathrm{R}_{\mathrm{n}} \quad=\text { nominal resistance } \\
& \mathrm{R}_{\mathrm{p}} \quad=\text { predicted capacity random variable } \\
& \mathrm{R}_{\mathrm{r}}=\text { ratio of projected rib area normal to bar axis to the product of the nominal bar } \\
& r \quad=R / R_{n}=X(1) R_{p} / R_{n} \\
& \mathrm{~s} \quad=\text { spacing of transverse reinforcement, in in. } \\
& \mathrm{T}_{\mathrm{b}}=\text { total force in a bar at development or splice failure, in } \mathrm{lb} \\
& \mathrm{T}_{\mathrm{s}} \quad=\text { contribution of confining steel to total bar force at bond failure } \\
& t_{d} \quad=0.72 d_{b}+0.28 \text {, term representing the effect of bar size on } T_{s} \\
& t_{\mathrm{r}} \quad=9.6 \mathrm{R}_{\mathrm{r}}+0.28 \text {, term representing the effect of relative rib area on } T_{S} \\
& \mathrm{~V}=\text { coefficient of variation } \\
& V_{R} \quad=\text { coefficient of variation for random variable for resistance } \\
& \mathrm{V}_{\mathrm{Q}} \quad=\text { coefficient of variation for random variable for total load } \\
& \mathrm{V}_{\mathrm{c}} \quad=\left(\mathrm{V}_{\mathrm{ccyl}}{ }^{2}+0.0084\right)^{1 / 2} \text {, assumed coefficient of variation for in-place concrete } \\
& \mathrm{V}_{\text {ccyl }} \quad=\sigma_{\text {ccyl }} / f^{\prime}{ }_{\text {cr }} \\
& \mathrm{V}_{\mathrm{m}} \quad=\text { coefficient of variation associated with the predictive equation (or model) itself } \\
& V_{Q_{D}} \quad=\text { coefficient of variation of random variable representing dead load effects }
\end{aligned}
$$




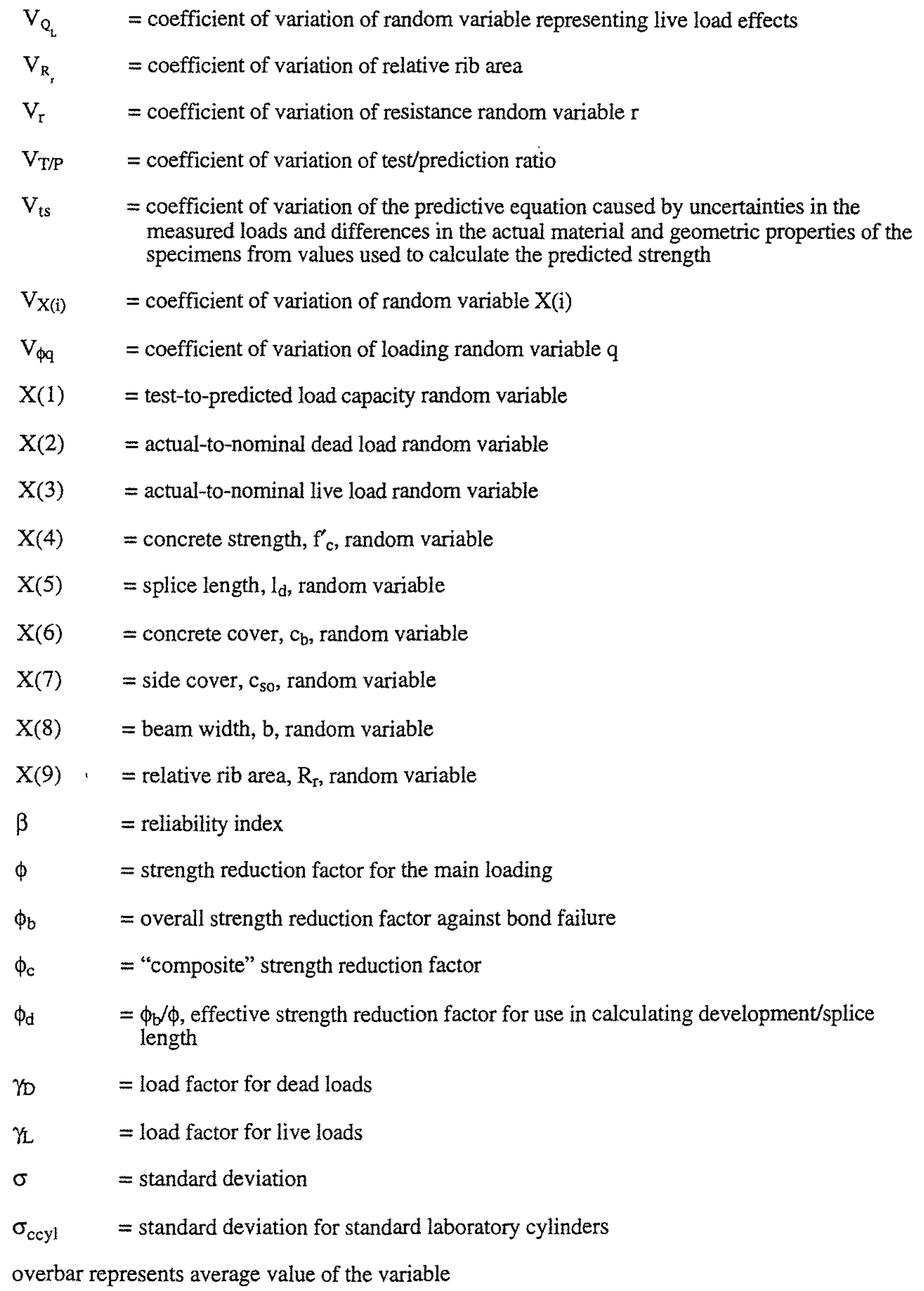

